ANA PAULA RIBEIRO RAZERA

\title{
PERCEPÇÃO DO CLIENTE QUANTO AO CUIDADO DE ENFERMAGEM NO PERÍODO PÓS-OPERATÓRIO
}

Dissertação apresentada ao Departamento de Enfermagem da Faculdade de Medicina UNESP, para obtenção do título de Mestre em Enfermagem.

Orientadora: Profa. Dra. Eliana Mara Braga

\section{Botucatu}

2010 
FICHA CATALOGRÁFICA ELABORADA PELA SEÇÃO TÉCNICA DE AQUISIÇÃO E TRATAMENTO DA INFORMAČ̃̃O

DIVISÃO TÉCNICA DE BIBLIOTECA E DOCUMENTAÇÃO - CAMPUS DE BOTUCATU - UNESP BIBLIOTECÁRIA RESPONSÁVEL: Selma Maria de Jesus

Razera, Ana Paula Ribeiro.

Percepção do cliente quanto ao cuidado de enfermagem no período pósoperatório / Ana Paula Ribeiro Razera. - Botucatu : [s.n.], 2010.

Dissertação (mestrado) - Enfermagem - Faculdade de Medicina de Botucatu, Universidade Estadual Paulista, 2010.

Orientadora: Eliana Mara Braga

Assunto CAPES: 40401006

1. Cuidados em enfermagem $\quad$ 2. Pós-operatório

CDD 610.73

Palavras-chave: Comunicação; Cuidados de enfermagem; Período pósoperatório 
"É Deus quem me ajuda, é o Senhor quem defende a minha vida. Senhor, de todo coração hei de vos oferecer o sacrifício e dar graças ao vosso nome, porque sois 6om". Salmo 53, 6-8. 
Dedicatória 


\section{A Deus,}

pelo seu amor incondicional, por dar-me discernimento e sabedoria nos momentos de dúvidas, pelas conquistas realizadas, pois sem Ele não chegaria onde estou.

"Tudo posso $\mathcal{N a q u e l e ~ q u e ~ m e ~ f o r t a l e c e " . ~}$

Filipenses 4:13

\section{Ao amor da minha vida, Paulinho}

meu marido e companheiro, por ser o homem que me faz a mulher mais feliz do mundo, pelo seu amor, paciência e confiança, por sempre manter-se ao meu lado superando cada obstáculo. Incentivando-me a acreditar que no final tudo vai dar certo. Te amo e sempre te amarei!!!

\section{Aos meus pais, Sérgio e Otilia,}

pelo meu existir, pela dedicação em me educar e ensinar qual caminho seguir, pelo incentivo e apoio em todos esses anos, pelo amor e carinho com que me criaram. Amo muito vocês!

A minha irmã, Natalia,

pelo companheirismo, amizade, preocupação, pelos dias de alegria e tristeza, poriluminar a minha vida.

Você é uma joia rara em minha vida! 
Agradecimento Especial 
À professora Doutora Eliana Mara Braga, minha orientadora e fada madrinha, por acreditar em mim e fazer minha estrela brilhar. Aquela que dividiu seus conhecimentos e, com sua sabedoria, abriu novos caminhos rumo à satisfação de meus ideais profissionais, incentivando sempre o meu caminhar.

Minha enorme admiração pelo seu caráter profissional e pela sua delicadeza em um dia ter me acolfido. Agradeço pela paciência, compreensão, disponibilidade, incentivo e amizade que me proporcionou. Obrigado por tornar meu sonho realidade! 
Agradecimentos 
À minha madrinha, Sueli, pelos ensinamentos e oraçães, carinho e dedicação, por me ajudar nos momentos difíceis, por ser uma mãezona pra mim.

Ao meu marido, Paulinho, obrigada pela perseverança, paciência, sugestões e correções. Só você sabe o quanto o resultado deste trabalho é precioso pra mim.

Aos meus sogros, Hélio e Ivani, pelo existir de meu "amor", pelo carinho em me acolher como família.

Aos meus cunhados e cunhadas, por trazerem mais alegria e felicidade à minha vida.

Ao meu anjinho Thiago, pelo presente que você é nas nossas vidas, por torná-la mais alegre e iluminada.

Às amigas, Marcela e Claudia, pelo companheirismo nos momentos de viagem, apoio e colaboração para que essa conquista se realizasse.

A todas as minhas amigas, pela amizade inestimável, colaboração e incentivo, e por me permitirem acreditar que tudo pode acontecer.

Às amigas Dra. Ângela e Dra. Maura, pelos ensinamentos, amizade e pelo estímulo oferecido para o meu crescimento, obrigada por dividirem comigo esse momento tão especial.

Às professoras Doutoras Wilza e Maria Alice, pelas valiosas sugestões, contribuições e carinho com que me receberam. 
Aos professores do curso de Mestrado do Departamento de Enfermagem, que ajudaram no meu crescimento profissional.

À Secretaria de Pós-Graduação da VNNESP, por tantos apelos atendidos a cada entrave burocrático.

À Secretária do Departamento de Enfermagem, Aline Parada, pelas dicas e paciência durante todo o curso.

Aos pacientes e familiares, pela colaboração para que este trabalho se concretizasse.

À equipe de enfermagem da Unidade de Internação Cirúrgica, que atenciosamente me recebeu, minha gratidão pela compreensão, apoio e carinho.

Enfim,

a todos que colaboraram para a realização deste estudo,

meus sinceros agradecimentos. 
Sumário 
APRESENTAÇÃO................................................................................ 13

RESUMO

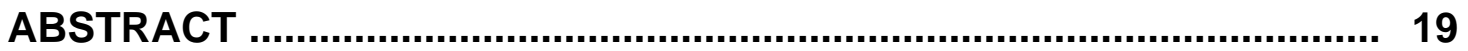

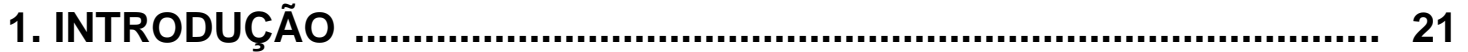

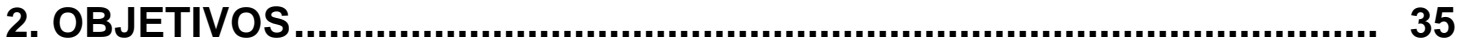

3. REFERENCIAL TEÓRICO DO ESTUDO ........................................... 37

4. MÉTODO............................................................................................... 42

4.1 Tipo de Estudo ............................................................. 43

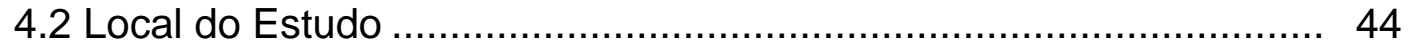

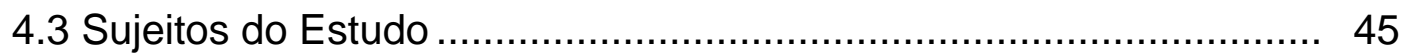

4.4 Procedimentos de Coleta de Dados .......................................... 45

4.5 Referencial Metodológico do Estudo ....................................... 47

5. RESULTADOS E DISCUSSÃO ……................................................. 53

5.1 Caracterização dos Entrevistados ................................... 54

5.2 Orientações fornecidas pela equipe de enfermagem no pós-

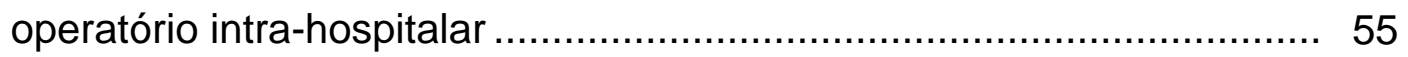

5.3 Análise Categorial Temática ........................................... 60

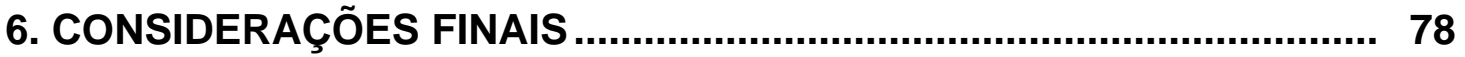

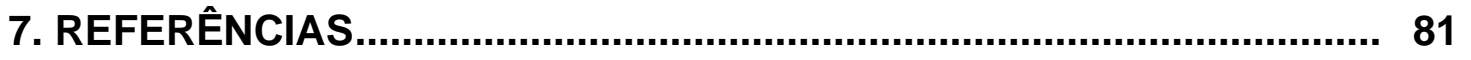

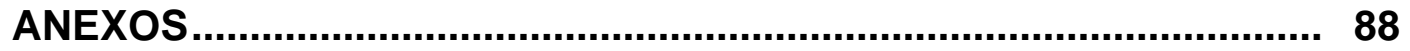

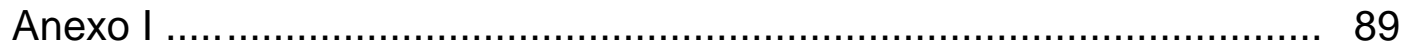

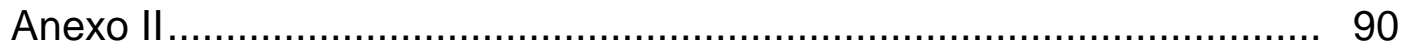

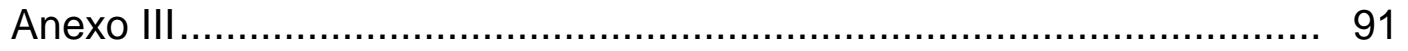

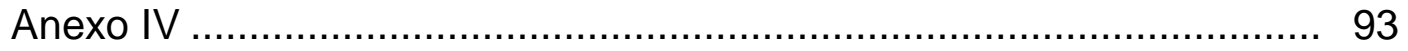


Apresentação 
Esta dissertação foi idealizada a partir de observações e percepções reunidas ao longo de minha trajetória acadêmica e profissional.

Concluí minha formação no ano de 2003 na vigésima terceira turma do Curso de Graduação em Enfermagem da Universidade do Sagrado Coração (USC) - Bauru. Em 2004, realizei o Aprimoramento Profissional pelo Hospital de Reabilitação de Anomalias Craniofaciais (CENTRINHO/USP) - Bauru, onde fui bolsista da FUNDAP e pude aperfeiçoar a prática e confecimento em diversos departamentos e áreas de Enfermagem, em especial no setor do Centro Cirúrgico. Em 2005, terminado o Aprimoramento Profissional, iniciei o curso de Especialização em Centro Cirúrgico e Centro de Materiais também pela Universidade do Sagrado Coração (USC). No mesmo ano, comecei a trabalhar na Unidade de Terapia Intensiva do Hospital Beneficência Portuguesa em Bauru, atuando como enfermeira supervisora e assistencial.

Em 2007, após completar o curso de Especialização, comecei a atuar no centro cirúrgico desse mesmo hospital na função de enfermeira assistencial, onde pude adquirir a experiência de realizar visitas pós-operatórias de enfermagem. No final do mesmo ano, iniciei minhas atividades nas enfermarias cirúrgicas e dei início ao Mestrado Profissional na Faculdade de Medicina de Botucatu - UNESP, para maior aprofundamento e desenvolvimento nessa área.

Desde o início de minha formação profissional, sempre me acompanhou uma inquietação a respeito da assistência dada ao paciente cirúrgico, pois muitas vezes pude observar uma clara falta de comunicação e interação da equipe de enfermagem 
com o paciente. Essas situações me incomodavam constantemente, pois observava que essa falta de humanização poderia refletir na qualidade da assistência durante o período de hospitalização desses clientes.

Em 2008 fui contratada para atuar na enfermaria cirúrgica de um hospital privado, quando tive a oportunidade de desenvolver este estudo. Assim, como enfermeira assistencial, preocupada em oferecer aos pacientes uma assistência competente, personalizada e humanizada, despertou-me o interesse em confecer as orientações de enfermagem recebidas no momento do planejamento dos cuidados pósoperatórios de pacientes cirúrgicos, buscando aprofundar os conhecimentos nessa área com a intenção de cuidar com qualidade das necessidades dos clientes e seus familiares. 
Resumo 
RAZERA APR. Percepção do cliente quanto ao cuidado de enfermagem no período pós-operatório. Botucatu, 2010. 93p. Dissertação (Mestrado) Departamento de Enfermagem - Faculdade de Medicina de Botucatu UNESP.

\section{RESUMO}

Este estudo teve como objetivo conhecer as orientações pós-operatórias fornecidas pela equipe de enfermagem a pacientes e/ou familiares de uma instituição privada e apreender a percepção destes indivíduos acerca das orientações recebidas. Foi um estudo transversal, com abordagem qualitativa, que utilizou o referencial teórico da Comunicação Interpessoal e o referencial metodológico da Análise de Conteúdo. Foram entrevistados 16 pacientes submetidos a procedimentos cirúrgicos eletivos, de urgência e/ou emergência que permaneceram, no mínimo, 3 dias internados. Os resultados evidenciaram que a equipe de enfermagem se preocupa com as técnicas instrumentais da profissão em si desconsiderando o indivíduo de forma holística, ou seja, além das necessidades físicas, as emocionais e espirituais. Também foi possível perceber que, quando o profissional enfermeiro permanece afastado do paciente e/ou não presta informações adequadas gera sentimentos de ansiedade, medo, insegurança e sensação de falta de cuidado. Por outro lado, quando a equipe de enfermagem se fez presente com cuidado e informações coerentes, os clientes relataram a sensação de ser bem cuidado. As conclusões deste estudo nos permitem considerar que a competência em comunicação é uma condição para o exercício da Enfermagem com qualidade e cidadania, que a capacitação em comunicação prepara a equipe de 
enfermagem para serem os profissionais exigidos pelos clientes do sistema de saúde e, finalmente, que a comunicação é um alicerce importante para que a relação de cuidado se estabeleça de forma efetiva e eficaz, proporcionando a compreensão do cliente em sua complexidade, com resultados qualitativos de atenção, dignidade e respeito ao ser cuidado.

Palavras-chave: comunicação; cuidados de enfermagem; período pósoperatório. 
Abstract 
Razera APR. Patient perception of nursing care in postoperative stage. Botucatu, 2010. 93p. Master's Dissertation - Departament of Nursing Botucatu School of Medicine - UNESP.

\section{ABSTRACT}

This study aims to identify the guidelines provided by the nursing team of a private institution to patients and family as well as learn with their perception of the aid received. It consists of a cross-sectional study with qualitative approach based on a theoretical reference of Interpersonal Communication and methodological reference of Content Analysis. 16 patients underwent elective surgical procedures of emergency and remained in the hospital for at least 3 days. Results showed that the nursing team is concerned about the instrumental techniques of the job disregarding the patient as a holistic individual, that is, besides their physical, emotional and spiritual needs. When the nurses stayed away from patients and did not provide appropriate guidelines which caused anxiety, fear and feeling of neglect. On the other hand, when nurses were present providing coherent care and assistance, patients reported to feel well cared. This study concluded that communicative competence is an essential condition for nurses to offer qualified assistance. Good communicative skills enable the nursing team to be the professionals required by the patients of the health system and are fundamental to provide effective care, resulting in the patients' comprehension that are assisted with attention, dignity and respect.

Key words: communication; nursing care; postoperative stage. 


\section{Introdução}


A expectativa que o indivíduo tem em relação à hospitalização, ao tratamento e à qualidade do cuidado é um fator que pode repercutir na sua recuperação.

O cuidado é como um ato de interação, constituído de ações e atividades de enfermagem dirigidas ao paciente e com ele compartilhadas, envolvendo o diálogo, o ouvir, a ajuda, a troca, o apoio, o conforto, a descoberta do outro, esclarecendo dúvidas, cultivando a sensibilidade, valorizando-o e compreendendo-o ${ }^{(1)}$.

O cuidado é também o desenvolvimento de ações, atitudes e comportamentos com base em conhecimento científico, experiência, intuição e pensamento crítico, realizado para e com o paciente/ser, para promoção, manutenção e/ou recuperação de sua dignidade. É o atributo mais valioso que a Enfermagem tem a oferecer à humanidade, pois trata-se da essência da Enfermagem e denota reciprocidade entre o enfermeiro e a pessoa. Está baseado em valores humanísticos e comportamento altruísta, desenvolvido por meio do exame dos pontos de interação com várias culturas e experiências pessoais. É uma forma de relação compreensiva e pode ser desenvolvido a partir do exame dos pontos de vista da pessoa, de suas crenças e valores, assim como da forma como interage com outras culturas e outras experiências de vida ${ }^{(2)}$.

Entendemos a Enfermagem como uma ciência humana empenhada no cuidar da pessoa sadia ou doente. O ato de cuidar implica no estabelecimento de interação entre sujeitos que cuidam e são cuidados, sujeitos que participam da realização de ações que são a verdadeira essência da Enfermagem. Isso 
porque, ao cuidarmos do outro, estamos realizando não somente uma ação técnica como também sensível, que envolve o contato entre humanos a partir do toque, do olhar, do ouvir, do olfato, da fala. Estas ações envolvem a sensibilidade própria dos sentidos e também a liberdade, a subjetividade, a intuição e a comunicação ${ }^{(3)}$.

Nessa perspectiva, o cuidado prestado contribui para uma ação terapêutica das mais eficazes, capaz de não só curar o corpo mas trazer também o conforto ao espírito. O cuidado, que traz no seu contexto a objetividade da técnica e a subjetividade da criação, incentiva a equipe de enfermagem a refletir e olhar de forma genuína a vida, melhorando a qualidade para aqueles que física ou emocionalmente dependem dela. É nesse cotidiano do cuidar que a relação dialógica enfermagem - cliente pode resultar em apoio, equilíbrio e bem-estar ${ }^{(4)}$.

A importância atribuída pelo paciente ao enfermeiro como uma presença de caráter humanizado pode ser entendida por meio dos significados do cuidar. Cuidar é ajudar o paciente a crescer, a enfrentar momentos difíceis, mantendose disponível, presente e solidário. Essa presença é percebida tanto pelo próprio ato de estar presente, pronta e abertamente, como pela interação estabelecida por meio da conversa, do tom de voz, da postura, dos gestos, do toque ou da própria expressão facial, transmitindo o calor humano(5).

Assumir um comportamento humanizado na assistência de enfermagem é considerar o ser humano como indivíduo que pertence à sociedade, com seu conhecimento, espiritualidade, cultura e sentimentos. Isso significa tratar a 
pessoa que está sob cuidados com respeito, por meio de valores éticos, a fim de garantir sua individualidade e condição de sujeito social ${ }^{(6)}$.

Apesar de toda a proposta lógica do processo de enfermagem, atualmente nos parece que a essência da profissão de Enfermagem, que é a arte de cuidar, não tem sido priorizada nos serviços de saúde.

É importante ressaltar que, muitas vezes, devido à sobrecarga imposta pelo cotidiano do trabalho, a enfermagem presta uma assistência mecanizada e tecnicista, não-reflexiva, esquece-se de humanizar o cuidado justamente por entender que em si o cuidado deve ser humanizado. Da mesma maneira, as relações de trabalho, em função de fatores internos e externos à enfermagem, vêm- se dando de modo pouco humanizado, interferindo diretamente na própria $\operatorname{assistência(7)~}^{(7}$

A humanização é uma expressão que vem sendo comumente usada no sentido de associação dos recursos tecnológicos ao reconhecimento da individualidade do paciente, compreendido como ser integral e ao mesmo tempo singular em suas necessidades. Considerando que a humanização do cuidado em enfermagem vem sendo bastante enfatizada nas instituições de saúde, e que a comunicação permite à equipe compreender as necessidades do paciente vulnerabilizado pela doença e hospitalização, surge a necessidade de refletir a respeito da relevância da comunicação no processo do cuidar humanizado em enfermagem ${ }^{(8)}$.

O objetivo de humanizar é tão intenso que chega a ser colocado como um desafio, por estar relacionado com qualidade e custos de internação. Desafio porque se cria o "paradoxo tecnológico da saúde", uma vez que as 
novas tecnologias melhoram a eficiência dos tratamentos à custa de procedimentos mais caros. Com isso, as instituições de saúde têm o compromisso de oferecer serviços de qualidade e atendimento humanizado ${ }^{(9)}$.

Com o avanço tecnológico e científico e a modernização de procedimentos vinculados ao estabelecimento de controle, o enfermeiro passou a assumir cada vez mais encargos administrativos. Com isso, surgiu a necessidade de resgatar os valores humanísticos da assistência de enfermagem. $\mathrm{O}$ atendimento dedicado ao paciente se distancia demasiadamente da teoria, já que, na prática, em várias situações a atenção individualizada é praticada de forma mecânica ${ }^{(10)}$.

A individualização do cuidado implica na adoção, pelo enfermeiro, de um conjunto de crenças e valores que enfatizam o ser humano e o consideram como cidadão, mas que nem sempre fazem parte do dia-a-dia da prática nas instituições de saúde ${ }^{(11)}$.

Os órgãos governamentais também apresentam preocupação com essa causa, o que culminou na criação do Programa Nacional de Humanização da Assistência Hospitalar (PNHAH), cujo objetivo é aprimorar as relações entre os profissionais da saúde e os usuários dos serviços de saúde, dos profissionais entre si e do hospital com a comunidade. O programa propõe um conjunto de ações interligadas com o intuito de modificar o padrão da assistência prestada aos usuários nos hospitais públicos do Brasil, assim como melhorar a qualidade e a eficácia dos serviços ${ }^{(12)}$. 
É fundamental agregarmos à competência técnica e científica uma ética que considere e respeite a singularidade das necessidades do usuário e do profissional, que aceite os limites de cada um na situação que requer a produção de atos em saúde. Nesse sentido, o Código de Ética dos profissionais de enfermagem estabelece que:

\begin{abstract}
"o profissional de enfermagem respeita a vida, a dignidade $e$ os direitos da pessoa humana em todo seu ciclo vital, sem discriminação de qualquer natureza; assegura ao cliente uma assistência de enfermagem livre de danos decorrentes de imperícia, negligência ou imprudência; cumpre e faz cumprir os preceitos éticos e legais da profissão, exercendo a Enfermagem com justiça, competência, responsabilidade e

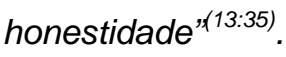

É importante conceituar ética para compreender-se o alcance de seu significado e a articulação entre a ética e a prática de enfermagem.

A ética, como estudo dos comportamentos humanos, refere-se a um dos mecanismos de regulação das relações sociais do homem que visa a garantir a coesão social e harmonizar interesses individuais e coletivos. Considera-se que todo paciente necessita ser tratado em virtude de suas necessidades de saúde, e não como um meio para a satisfação de interesses institucionais dos profissionais de saúde e da ciência. Para tanto, as instituições de saúde públicas e privadas devem focar suas ações e serviços direcionados no sentido de humanizar suas práticas ${ }^{(14)}$. Assim, a prestação de cuidados com fundamentação científica, a aplicação do processo de enfermagem, a integração entre a equipe e as técnicas de trabalho, como instrumentos constantes na prática diária, devem ser colocados a serviço da humanização 
hospitalar. Além disso, a execução de técnicas é uma excelente oportunidade para o diálogo sobre as ações de saúde preventiva, promoção da saúde e educação para a alta hospitalar ${ }^{(6)}$.

Para que o cuidado humano tenha efeito positivo, é necessário incorporar mais de um fator à sua estrutura, como a valorização da humanização, a criatividade na promoção da fé e da esperança, promoção do ensino-aprendizagem entre os profissionais, a prestação de cuidados, além da possibilidade de expressão de sentimentos ${ }^{(10)}$.

Dessa forma, para ampliar o atendimento de enfermagem é preciso que a equipe esteja conscientizada e preparada para fazer a diferença no cuidado, compreendendo o paciente na sua complexidade. Na dinâmica da assistência, o enfermeiro é responsável por orientar e sanar dúvidas pertinentes às intervenções, trazendo uma maior tranquilidade e segurança às pessoas atendidas.

Desse modo, o diálogo pode ser entendido como uma das ferramentas do cuidado humano, pois todos os sentimentos que afloram na relação cliente equipe de enfermagem são redimensionados. O ato da comunicação e a interação com o outro são capazes de gerar, por um lado, novas possibilidades de enfrentamento da doença pelo cliente e, por outro, um cuidar com sensibilidade, ou seja, com afeto, compaixão, responsabilidade e cumplicidade ${ }^{(4)}$.

A comunicação é parte relevante desse cuidar, e já não pode ser considerada apenas um dos instrumentos básicos da enfermagem ou do 
desenvolvimento do relacionamento terapêutico. Sendo assim, o enfermeiro, como coordenador da assistência, pode estabelecer um relacionamento mútuo de comunicação terapêutica envolvendo a equipe e o paciente cirúrgico para um cuidado de qualidade ${ }^{(1)}$.

Entendemos que a qualidade na área da saúde significa pensar que a instituição de saúde e os profissionais nela inseridos são responsáveis por preservar a vida das pessoas.

O enfermeiro é o profissional que coordena e gerencia todo o processo de assistência a ser desenvolvido em relação ao paciente e tudo o que o envolve no contexto da instituição hospitalar. $O$ paciente e suas especificidades, suas necessidades, sua alta ou recuperação, constituem a principal razão da assistência de enfermagem, a qual necessita, portanto, ser realizada eficientemente, com comprometimento de quem a desenvolve, garantindo qualidade do cuidado prestado e, principalmente, a satisfação do paciente e seus familiares ${ }^{(15)}$.

Reconhecer os sentimentos do indivíduo é fundamental para o enfermeiro, pois é a partir dessa compreensão que ele percebe as necessidades do paciente e pode realizar um plano de cuidado sistematizado, considerando a pessoa como um todo e desenvolvendo postura empática. Nesse sentido, uma comunicação competente é considerada como um poderoso instrumento para se prestar assistência $\operatorname{adequada}^{(16,17)}$.

Ser competente em comunicação é uma habilidade fundamental a ser adquirida pelo enfermeiro, sendo ele docente ou atuante em outra atividade da 
prática do cuidar. Essa habilidade Ihe possibilitará um cuidar consciente, verdadeiro e transformador ${ }^{(17)}$.

Sabemos que o uso ineficaz da comunicação e a carência de cuidado por parte de alguns profissionais implicam uma série de problemas que podem repercutir nas condições de vida do indivíduo.

Dificilmente teremos todo o tempo que desejamos para atender um paciente, por isso os pequenos momentos devem ser bem aproveitados para que possamos, assim, melhorar a nossa assistência e individualizar o cuidado. Um enfermeiro que opta apenas pelo cuidado físico desconhece que o nível de satisfação do paciente está relacionado, também, com a comunicação realizada durante a prestação da assistência de enfermagem ${ }^{(18)}$.

Na área da saúde, a comunicação é um instrumento essencial para ser utilizado diariamente no contato com os pacientes, familiares e outros profissionais. É, portanto, uma necessidade básica do ser humano, do homem social $^{(19)}$.

É fundamental saber lidar com gente, pois somente pela comunicação efetiva é que o profissional poderá ajudar o paciente. Especialmente o enfermeiro, por interagir diretamente com o paciente, precisa estar mais atento ao uso adequado das técnicas da comunicação interpessoal ${ }^{(20)}$.

A comunicação interpessoal é um instrumento importante a ser utilizado durante a avaliação do paciente, com o objetivo de coletar dados para a realização da evolução de enfermagem. A evolução é vista como uma fase de avaliação do processo de cuidar do paciente, e fornece informações diretas a 
respeito da qualidade do cuidado prestado, facilitando a verificação da satisfação do paciente e a sistematização da assistência(11).

A centralidade da comunicação como parte da assistência de enfermagem vem sendo reconhecida de forma crescente desde o advento da Enfermagem moderna, pois Florence Nigthingale já demonstrava a preocupação e dificuldade de se estabelecer uma comunicação real com o cliente $^{(21)}$.

A maneira de falar e o que falamos têm especial importância no momento da avaliação, pois o uso de termos técnicos pode aumentar a insegurança do paciente que desconhece tal linguagem. A linguagem pode variar de acordo com o nível sociocultural, a região do país, a idade, entre outros fatores. Portanto, é importante estarmos abertos para ouvir diferentes termos e saber interpretá-los adequadamente, validando-os, se necessário, para que seja feita uma avaliação correta da história e necessidades do paciente. Estar consciente e atento ao fato de que não nos comunicamos apenas com palavras aumenta nossa percepção em relação ao cuidado com o aspecto não-verbal nas interações com os pacientes, tornando-nos assim mais vigilantes quanto às diversas reações apresentadas por eles ${ }^{(20)}$.

Mediante o processo de adoecimento, quando o diagnóstico é cirúrgico e requer a hospitalização, emergem condições que alteram a segurança emocional, gerando uma série de medos, tais como: medo do desconhecido; da anestesia; de não acordar mais; de perder a integridade física e o controle da consciência e, com isso, relatar segredos que não desejaria revelar; além do medo da dor e da cirurgia ${ }^{(22)}$. 
Nesse sentido, o paciente cirúrgico exige cuidados de enfermagem fundamentados nas necessidades evidentes e/ou potencializadas pela iminência do procedimento anestésico cirúrgico ou pelas ocorrências oriundas da dinâmica do preparo do ambiente, do indivíduo, respeitando seus valores e promovendo interações para melhorar sua condição de enfrentamento da cirurgia $^{(22)}$.

A assistência de enfermagem perioperatória é prestada de forma organizada pelos enfermeiros, embora, na maioria das vezes, não exista um registro ou uma documentação que norteie as suas etapas e que também garanta a sua continuidade. Assim, a assistência acaba sendo uma atividade profissional individual, o que dificulta sua sistematização. O paciente e a família têm papel essencial na formulação dos objetivos e na implementação da assistência a ser prestada, mas é a instituição de saúde que define a filosofia da assistência e, portanto, define também a maneira como a dimensão do cuidar estará inserida em um contexto com valores e crenças de ordem mais ampla $^{(6)}$.

Sabe-se que usuários e familiares esperam que os profissionais sejam responsáveis pela diminuição do sofrimento, da angústia, da dor, assim como desejam ser acolhidos, amparados e não responsabilizados pela situação em que se encontram. Por outro lado, os profissionais também têm dificuldades para lidar com suas próprias limitações, sentimentos conflitantes que surgem diante de cada situação, temores e angústias desencadeados pelos dilemas de difícil resolução com os quais se deparam, e nem sempre contam com 
infraestrutura que ofereça suporte técnico, emocional e ético para suas decisões $^{(22)}$.

Diante disso, a visita pós-operatória, como um sistema de assistência continuada, participativa, integral e documentada, destaca-se como uma estratégia de avaliação da assistência prestada, procurando atender aos requisitos de qualidade, na visão do paciente e/ou familiares, sobre a assistência transoperatória ${ }^{(6,11)}$.

A visita pós-operatória proporciona ao enfermeiro oportunidade de avaliar os resultados da assistência transoperatória, desenvolver interação com o paciente e familiar/acompanhante, estabelecer comunicação entre os enfermeiros das unidades de internação, promover a continuidade da assistência e prestar cuidado de enfermagem individualizado ao paciente ${ }^{(23)}$.

As finalidades da visita pós-operatória de enfermagem são: identificar problemas, percepções e expectativas que demandem ações de enfermagem; conhecer hábitos individuais que facilitem a sua adaptação à unidade e ao tratamento; estabelecer uma relação interpessoal; tentar abranger a totalidade do paciente nos seus aspectos biopsicossocioespirituais; individualizar a assistência de enfermagem; fornecer subsídios para a tomada de decisão quanto às condutas de enfermagem; avaliar a evolução das condições do paciente para detectar alterações ou tendências na sua situação saúdedoença; esclarecer dúvidas ou falhas no entendimento, reforçando informações já prestadas; reduzir o nível de ansiedade do paciente ${ }^{(24)}$. 
A visita pós-operatória inicia-se com a coleta de dados levantados do prontuário sobre a evolução operatória do paciente, verificando a presença ou não de infecção na incisão cirúrgica, intercorrências quanto ao posicionamento cirúrgico e adaptação dos eletrodos da placa de bisturi e a fixação de drenos, sondas e catéteres. O enfermeiro entrevista o paciente/familiar, dando oportunidade para que expressem seus sentimentos quanto à assistência perioperatória. Nesse sentido, é imprescindível que o enfermeiro se comprometa com a atualização na sua área de domínio, capacitando-se para identificar as necessidades do paciente, entender seus processos fisiológicos e emocionais, para que tenha condições de planejar, supervisionar, avaliar e garantir a qualidade da assistência prestada ${ }^{(11)}$.

Sabemos que cada pessoa apresenta uma reação diferente diante de situações idênticas, o que exige da enfermagem preparo para o bom relacionamento com o paciente, proporcionando atitudes competentes e capacidade de sentir as necessidades humanas para satisfazê-las com respeito e dignidade. Reconhecemos que o paciente espera cuidados especiais e solução para os seus problemas, pois a realização de uma cirurgia é um acontecimento importante na vida de uma pessoa, encerra um significado próprio e, por meio dela, essa pessoa espera viver de forma mais saudável e com melhor qualidade de vida ${ }^{(25)}$.

Portanto, acreditamos que as visitas pós-operatórias realizadas pelo enfermeiro com comunicação competente poderão proporcionar cuidado adequado, além de condições de avaliação e resolubilidade do trabalho. 
Diante da revisão de literatura apresentada e para responder às minhas inquietações, tenho como finalidade neste estudo tomar conhecimento das orientações de enfermagem recebidas por pacientes e familiares no momento dos cuidados pós-operatórios, com a intenção de cuidar com competência das necessidades individuais dos clientes e de seus familiares. 
2. Objetivos 
- Conhecer as orientações pós-operatórias fornecidas pela equipe de enfermagem a pacientes e/ou familiares de uma instituição privada.

- Apreender a percepção desses indivíduos acerca das orientações recebidas. 


\section{Referencial Teórico do Estudo}


Para atingir os objetivos propostos, este estudo baseou-se no referencial teórico da comunicação interpessoal, verbal e não-verbal, segundo Silva ${ }^{(20)}$, Stefanelli e Carvalho ${ }^{(26)}$.

Várias são as abordagens teóricas da comunicação no contexto da Enfermagem. Dentre elas estão as teorias da comunicação interpessoal, comunicação em pequenos grupos, nas organizações humanas e de massa ${ }^{(27)}$.

Destacamos neste estudo as teorias que tratam da comunicação interpessoal, pois buscam compreender a natureza do estabelecimento e manutenção das relações, os padrões estabelecidos nas relações que são movidas pelas necessidades interpessoais de inclusão, controle e afeição, o processo de percepção interpessoal que se estabelece nas interações e como se dá a apresentação do eu a outros, como os interlocutores se percebem e se compreendem, ou seja, como se dá o complexo processo de percepção social, os graus variados de atração ou rejeição no relacionamento, e, finalmente, o conflito social que pode resultar da comunicação interpessoal ou levar a esta. Pelas suas características, esse contexto tem sido um dos mais estudados na Enfermagem, em especial na relação enfermeiro-paciente. Nem sempre os achados desses estudos têm sido considerados positivos, pois são inúmeros os exemplos de afastamento ou distanciamento de pacientes, ou de uso de comportamentos autoritários ou assimétricos ${ }^{(26)}$.

Considera-se que o conhecimento das dimensões de assertividade, responsividade e versatilidade do estilo de comunicação de uma pessoa, e da comunicação do outro com quem interage, seja necessário para maximizar os objetivos da comunicação(26). 
$\mathrm{Na}$ área da saúde, é fundamental saber interagir com pessoas, pois a todo momento, pelos corredores dos hospitais, nos ambulatórios, salas de emergência, leitos de pacientes e salas de cirurgias, surgem conflitos originados de uma atitude não-compreendida ou mesmo de uma reação inesperada. É de se esperar que isso aconteça porque os profissionais da área da saúde têm como base do seu trabalho as relações humanas, sejam elas com o paciente e seus familiares ou com a equipe multidisciplinar. Assim, não se pode pensar na ação profissional sem levar em consideração a importância do processo comunicativo nela inserido. Nesse sentido, a escrita, a fala, as expressões faciais, a audição e o tato são formas de comunicação amplamente utilizadas, mesmo que não sejam usados de forma consciente ${ }^{(20)}$.

Cabe ao profissional da saúde decodificar, decifrar e perceber o significado da mensagem que o paciente envia, para só então estabelecer um plano de cuidado adequado e coerente com as suas necessidades. Para tanto, é preciso estar atento aos sinais de comunicação verbais e não-verbais emitidos pelos pacientes e seus familiares, pois desse modo pode-se estabelecer uma comunicação adequada, capaz de diminuir conflitos, malentendidos e atingir objetivos para a solução dos problemas detectados na interação com os pacientes ${ }^{(20)}$.

A comunicação interpessoal pode ser dividida em comunicação verbal e não-verbal, como descrito a seguir:

A comunicação verbal é associada às palavras expressas, por meio da linguagem escrita ou falada. Quando interagimos verbalmente com alguém, 
estamos tentando nos expressar transmitindo, clarificando ou validando a compreensão de algo.

Para a expressão, as técnicas são: permanecer em silêncio, verbalizar aceitação, repetir as últimas palavras ditas pela pessoa, ouvir reflexivamente ou verbalizar interesse.

$\mathrm{Na}$ clarificação podem ser utilizadas técnicas como: estimular comparações, devolver as perguntas feitas e solicitar esclarecimento de termos incomuns e de dúvidas.

No que se refere à validação, podem ser utilizadas estratégias como: repetir a mensagem dita e pedir à pessoa para repetir o que foi dito. A experiência e as propostas teóricas mostram que a não-validação da comunicação é uma das causas da falta de compreensão entre as pessoas.

A comunicação não-verbal ocorre na interação pessoa-pessoa, exceto as palavras por elas mesmas. Sua função é complementar, contradizer e substituir a comunicação verbal, além de demonstrar sentimentos. Pode também ser definida como toda informação obtida por meio de gestos, posturas, expressões faciais, orientações do corpo, singularidades somáticas naturais ou artificiais, organização dos objetos no espaço e até pela relação de distância mantida entre os indivíduos ${ }^{(20)}$.

A premissa básica da comunicação não-verbal é que o indivíduo participa simultaneamente de duas dimensões existenciais, decorrentes de dois modos de se relacionar com o mundo: uma verbal, que lhe confere um estatuto psicolinguístico, e outra não-verbal, com um estatuto psicobiológico ${ }^{(20)}$. 
A comunicação é um processo de compreender e compartilhar mensagens enviadas e recebidas, e as próprias mensagens e o modo como se dá o seu intercâmbio exercem influência no comportamento das pessoas envolvidas em curto, médio e longo prazo. Essa influência pode ser percebida mesmo quando as pessoas estão em total silêncio, distantes umas das outras ou do ambiente no qual o processo de comunicação ocorre. Isso permite afirmar que as pessoas encontram-se constantemente envolvidas por um campo interacional. É esse intercâmbio de mensagens, trocas, percepção e interpretação que permite às pessoas formar a imagem delas mesmas, do outro e do mundo à sua volta ${ }^{(20,26)}$.

É nesse campo interacional, em determinado contexto, que as pessoas se percebem, partilham o significado de ideias, pensamentos e propósitos, alterando ou mantendo seus significados num processo de interação com os outros e o ambiente, o que Ihes permite traçar metas e visualizar meios para atingi-las, destacando-se, assim, a necessidade do enfermeiro estar capacitado e com intenção resolutiva para enfrentar as dificuldades advindas desse processo, pois este Ihe traz uma clientela cheia de incertezas diante de mudanças cotidianas ${ }^{(26)}$.

Com base no referencial teórico mencionado, pretendemos compreender como as orientações pós-operatórias fornecidas pela equipe de enfermagem a pacientes e/ou familiares podem influenciar na qualidade do cuidado, bem como se esta comunicação é percebida e acolhida pelos clientes. 


\section{Método}




\subsection{Tipo de Estudo}

Trata-se de um estudo com abordagem qualitativa, com o qual se pretende compreender o fenômeno de acordo com o ponto de vista do sujeito.

O método qualitativo é o que se aplica ao estudo da história, das relações, das representações, das crenças, das percepções e das opiniões, produtos das interpretações que os humanos fazem a respeito de como vivem, constroem seus artefatos e a si mesmos, sentem e pensam. Embora já tenham sido usadas para estudos de aglomerados de grandes dimensões, as abordagens qualitativas conformam melhor as investigações de grupos e segmentos delimitados e focalizados, de histórias sociais sob a ótica de atores, de relações e para análises de discursos e de documentos ${ }^{(28)}$.

A pesquisa qualitativa responde a questões muito particulares e se ocupa, nas Ciências Sociais, com um nível de realidade que não pode ou não deveria ser quantificado, ou seja, trabalha com o universo dos significados, dos motivos, das aspirações, dos valores e das atitudes. Este conjunto de fenômenos humanos é entendido aqui como parte da realidade social, pois o ser humano se distingue não só por agir, mas por pensar sobre o que faz e por interpretar suas ações dentro e a partir da realidade vivida e partilhada com seus semelhantes. O universo da produção humana, que pode ser resumido no mundo das relações, das representações e da intencionalidade e é objeto da pesquisa qualitativa, dificilmente pode ser traduzido em números e indicadores quantitativos $^{(29)}$. 
Esse tipo de método que tem fundamento teórico, além de permitir desvelar processos sociais ainda pouco conhecidos referentes a grupos particulares, propicia a construção de novas abordagens, revisão e criação de novos conceitos e categorias durante a investigação. Caracteriza-se pela empiria e pela sistematização progressiva de conhecimento até a compreensão da lógica interna do grupo ou do processo em estudo. Por isso, é também utilizado para a elaboração de novas hipóteses, construção de indicadores qualitativos, variáveis e tipologias ${ }^{(28)}$.

\subsection{Local do Estudo}

O estudo foi desenvolvido nas enfermarias cirúrgicas de um hospital privado localizado em um município do interior do Estado de São Paulo com capacidade de 195 leitos. Essa instituição conta com um quadro de recursos humanos de enfermagem, totalizando 400 funcionários. Atende aproximadamente 12.000 pacientes por ano em diversas especialidades, ou seja, apresenta uma rotatividade média de 32 pacientes por dia. Para atender aos objetivos deste estudo, num segundo momento ele foi desenvolvido nos domicílios dos pacientes. 


\subsection{Sujeitos do Estudo}

Os sujeitos deste estudo foram 16 pacientes submetidos a procedimentos cirúrgicos eletivos, de urgência e/ou emergência que permaneceram, no mínimo, 3 dias internados. Segundo este critério, foram selecionados indivíduos maiores de 18 anos, de ambos os sexos e com nível de consciência que os possibilitasse a compreensão da pesquisa e assinatura do Termo de Consentimento Livre e Esclarecido. Cabe ressaltar que foram considerados sujeitos do estudo, além dos pacientes, os familiares cuidadores acompanhantes, quando os pacientes eram idosos que se comunicavam pouco e/ou tinham alguma dificuldade de expressão. Desse modo, foram entrevistados 13 pacientes cirúrgicos e 3 familiares, perfazendo um total de 16 sujeitos participantes.

\subsection{Procedimentos de Coleta de Dados}

Inicialmente, o projeto de pesquisa foi encaminhado para apreciação do Comitê de Ética em Pesquisa (CEP) para avaliação. Após parecer favorável do mesmo, segundo ofício $n^{\circ} 272 / 2008$ (ANEXO I) foi solicitada aos participantes do estudo a assinatura do Termo de Consentimento Livre e Esclarecido (ANEXO II) de acordo com a resolução 196/96 do Ministério da Saúde(30).

Para atender aos objetivos propostos no estudo foram elaborados dois instrumentos para coleta de dados, divididos em duas etapas: o primeiro 
instrumento foi um roteiro de entrevista semiestruturada, com questões abertas que complementavam a finalidade do estudo.

Essa entrevista foi realizada por meio do formulário acima citado, com questões aplicadas nas visitas pós-operatórias para pacientes submetidos a procedimentos cirúrgicos no período de setembro de 2008 a março de 2009, momento em que tomávamos conhecimento das orientações de enfermagem recebidas no pós-operatório pelos pacientes e/ou familiares (ANEXO III).

A elaboração do questionário foi realizada pela pesquisadora, visto que na instituição investigada não havia um instrumento sistematizado para esse fim. O instrumento continha as opiniões dos pacientes e/ou familiares em relação às orientações de enfermagem recebidas no pós-operatório, e foi aplicado a partir do terceiro dia de pós-operatório, antes da alta hospitalar.

Nessa primeira etapa, cada entrevista durou em média 20 minutos, desde o momento da abordagem e apresentação da pesquisa até a finalização e agradecimento pela participação.

A segunda etapa do estudo foi realizada após 40 dias da alta do paciente, momento em que marcávamos uma nova entrevista por telefone e nos dirigíamos ao domicílio dos mesmos, utilizando o formulário pós-alta hospitalar (ANEXO IV), com as seguintes questões norteadoras:

- Como você se sentiu durante a internação para a realização da cirurgia?

- $\mathrm{Na}$ sua opinião, as orientações recebidas no pós-operatório significaram que existe um cuidado de enfermagem adequado? 
Nessa segunda etapa, as entrevistas foram gravadas em aparelho de áudio digital, dirigida a pacientes e/ou familiares. Na sequência, para melhor análise, o conteúdo das gravações foi transcrito, sendo destruído após o término da pesquisa.

A participação neste estudo foi voluntária. Sendo assim, 2 pacientes recusaram-se a participar da segunda etapa do estudo, mesmo após assinatura do Termo de Consentimento Livre e Esclarecido e conhecimento da pesquisa. Cabe ressaltar que esta recusa ocorreu durante a visita domiciliar, pós-alta hospitalar, na residência de 2 idosos, em que os filhos cuidadores sentiram-se constrangidos em responder questões sobre a avaliação do cuidado, alegando preocupações com a manutenção do convênio com a empresa em que trabalhavam e também por ser aquela uma instituição privada reconhecida no município.

\subsection{Referencial Metodológico do Estudo}

O material trabalhado fundamentou-se nos diálogos desenvolvidos por meio de entrevistas, e partindo da premissa de que tudo o que é dito ou escrito é passível de ser submetido a análise de conteúdo. Foi escolhida, dentre as técnicas propostas, a análise temática para instrumentalizar e operacionalizar a análise de conteúdo das entrevistas concedidas pelos sujeitos participantes deste estudo. 
A análise dos resultados das entrevistas foi realizada segundo a proposta de Análise de Conteúdo de $\operatorname{Bardin}^{(31)}$, que define a análise de conteúdo como:

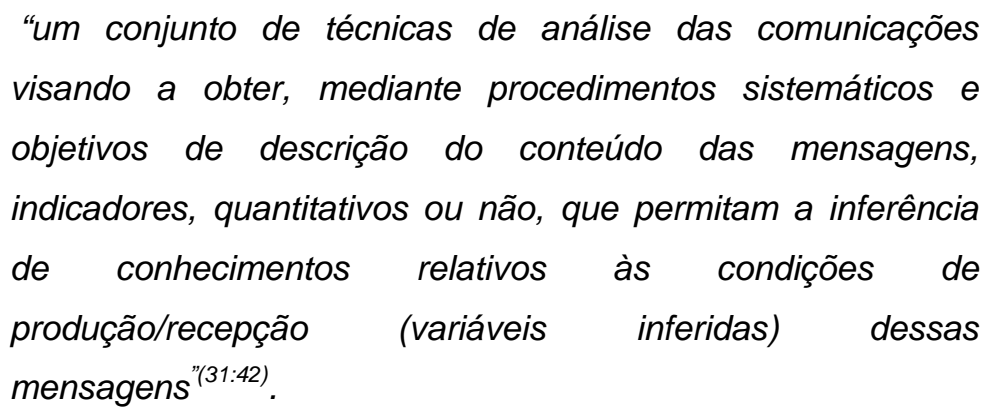

O fundamento da especificidade da análise de conteúdo reside na articulação entre a superfície dos textos, descrita e analisada (pelo menos alguns elementos característicos) e os fatores que determinam essas características, deduzidos logicamente ${ }^{(31)}$.

A análise de conteúdo trabalha as palavras e suas significações, procurando conhecer o que está por trás das palavras analisadas ${ }^{(31)}$.

A técnica é constituída por três fases: a pré-análise, a descrição analítica e a interpretação inferencial.

A pré-análise é a fase de organização do material e a sistematização de ideias iniciais em um plano de análise. Nessa fase, faz-se a transcrição das entrevistas na íntegra e uma leitura flutuante dos textos, tomando contato exaustivo com o material. Além da leitura flutuante, o pesquisador faz a escolha dos documentos, ou seja, procede a demarcação do universo de documentos sobre os quais proceder-se-á a análise, portanto constituindo o corpus, "conjunto de documentos tidos em conta para serem submetidos aos 
procedimentos analíticos". Corresponde a um período de intuições, mas tem por objetivo sistematizar as ideias iniciais, de maneira a conduzir a um esquema preciso do desenvolvimento das operações sucessivas, num plano de análise. Ainda nessa fase, podem-se formular hipóteses e objetivos, não sendo obrigatório o estabelecimento de hipóteses como guia ${ }^{(31)}$.

A seguir, na fase de descrição analítica, são feitos o recorte e a escolha das unidades de registro, elegendo-as e codificando-as mediante a convergência com o fenômeno. Como último procedimento da pré-análise, recomenda-se a preparação do material no sentido de reuni-lo, no caso de entrevistas gravadas. Estas devem ser transcritas na íntegra, facilitando a manipulação para análise. Dessa forma, classificamos as unidades temáticas sob um título genérico com base em um grupo de elementos, num processo chamado categorização ${ }^{(31)}$.

A categorização é uma operação de classificação de elementos constitutivos de um conjunto, por diferenciação e, seguidamente, por reagrupamento segundo o gênero (analogia), com critérios previamente definidos. As categorias são rubricas ou classes, as quais reúnem um grupo de elementos (unidades ou registros, no caso da análise de conteúdo) sob um título genérico, agrupamento este efetuado em razão dos caracteres comuns desses elementos ${ }^{(31)}$.

Esse procedimento é uma tentativa de se caminhar na objetivação durante a análise. Para que se tenha uma categorização, é importante que as categorias sejam homogêneas. Em outras palavras, cada categoria deve ser obtida a partir dos mesmos princípios utilizados para toda a categorização ${ }^{(31)}$. 
Os critérios para categorização podem ser: semântico ou temático, quando agrupados todos os temas com o mesmo significado; léxico, que corresponde à classificação das palavras segundo o seu sentido, com emparelhamento dos sinônimos e dos sentidos próximos; sintático, que agrupa verbos e adjetivos; e expressivo, que são as categorias que classificam as diversas perturbações da fala. Classificar elementos em categorias impõe à pesquisa o que cada um deles tem em comum com outro. $\mathrm{O}$ que vai permitir $\mathrm{O}$ agrupamento é a parte comum existente entre eles.

A categorização é a simplificação dos dados brutos, é um processo de estruturação dividido entre inventário (isolamento dos elementos) e classificação (repartição dos elementos, impondo uma organização das mensagens) que propiciam a passagem dos dados brutos para dados organizados.

A palavra categoria, em geral, refere-se a um conceito que abrange elementos ou aspectos com características comuns ou que se relacionam entre si. Essa palavra está ligada à ideia de classe ou série. As categorias são empregadas para estabelecer classificações, e trabalhar com categorias significa agrupar elementos, ideias ou expressões em torno de um conceito capaz de abranger tudo isso.

Um conjunto de categorias deve possuir as seguintes qualidades:

- Exclusão mútua: cada elemento não pode existir em mais de uma categoria; 
- Homogeneidade: o princípio de exclusão mútua depende da homogeneidade das categorias (um único princípio de classificação deve governar a sua organização);

- Pertinência: categoria está adaptada ao material de análise escolhido e pertence ao quadro teórico definido. O sistema de categorias deve refletir as intenções da pesquisa, as questões do pesquisador e/ou corresponder às características da mensagem;

- Objetividade e fidelidade: as diferentes partes de um mesmo material, ao qual se aplica a mesma categoria, devem ser codificadas da mesma maneira, mesmo quando submetidas a várias análises;

- Produtividade: um conjunto de categorias é produtivo se fornecer resultados bons em índices de inferências, em hipóteses novas e em dados exatos.

Portanto, a análise de conteúdo é mencionada como um conjunto de técnicas, indicando que há várias maneiras para analisar conteúdos de materiais de pesquisa, sendo uma delas a análise temática ${ }^{(31)}$.

$\mathrm{Na}$ análise temática, como o próprio nome indica, o conceito central é o tema. Este comporta um feixe de relações e pode ser representado por uma palavra, frase ou resumo ${ }^{(28)}$. De acordo com $\operatorname{Bardin}^{(31)}$ :

"o tema é a unidade de significação que se liberta naturalmente de um texto analisado segundo critérios relativos à teoria que serve de guia à leitura. Consiste em descobrir os núcleos de sentido que compõem a comunicação e cuja presença ou frequência de aparição pode significar alguma coisa para o objetivo analítico escolhido"(31:105). 
O tratamento dos resultados obtidos e interpretação é a fase em que os dados brutos são tratados de maneira a serem significativos e válidos. O analista, tendo à sua disposição resultados significativos e fiéis, pode então propor inferências e adiantar interpretações a propósito dos objetivos previstos, ou que digam respeito a outras descobertas inesperadas ${ }^{(31)}$. 
5. Resultados e Discussão 
A seguir, passamos a apresentar os resultados deste estudo, inicialmente, caracterizando os sujeitos segundo a faixa etária, sexo e tipo de procedimento cirúrgico. Em seguida, apresentaremos as orientações que foram fornecidas pela equipe de enfermagem no período pós-operatório intrahospitalar. E, finalmente, a análise categorial temática da percepção dos clientes e/ou familiares cuidadores sobre as orientações de enfermagem, ressaltando que, nessa etapa, as entrevistas foram realizadas nos domicílios dos pacientes.

\subsection{Caracterização dos Entrevistados}

Fizeram parte deste estudo 16 indivíduos na faixa etária de 26 a 82 anos, sendo que 3 pacientes com idade entre 64 e 74 anos estavam o tempo todo acompanhados de seus familiares cuidadores, os quais complementavam suas falas no momento das entrevistas intra-hospitalares e também domiciliares. Em relação ao sexo e estado civil, 11 eram do sexo feminino e 5 do sexo masculino, 9 casados, 2 solteiros, 2 viúvos e 3 separados.

De acordo com o tipo de cirurgia, 12 foram cirurgias eletivas, 3 de urgência e 1 de emergência, sendo que a maior parte delas se concentrou nas especialidades de gastroenterologia e ortopedia e todas ocorreram sem intercorrências no ato anestésico cirúrgico. O tempo médio de permanência dos pacientes em hospitalização foi de 6 dias. 
Os clientes foram entrevistados pela pesquisadora após 72 horas do procedimento cirúrgico, em local privativo, dentro da Unidade de Internação. A entrevistadora se apresentou como aluna do curso de pós-graduação em Enfermagem da FMB-UNESPI Botucatu e, ao final de cada entrevista, transmitiu as informações que os clientes demonstraram desconhecer e querer saber, anotando dados relevantes em relação à cirurgia para apoiar a segunda fase da coleta de dados.

\subsection{Orientações fornecidas pela equipe de enfermagem no pós-operatório intra-hospitalar}

Na primeira etapa do estudo, dos 16 participantes, 10 confirmaram ter recebido orientações pós-operatórias de enfermagem, porém não conseguiram identificar o profissional que os orientou. As orientações percebidas com mais significância foram sobre a realização e limpeza do curativo cirúrgico.

O fato de não identificarem o profissional responsável pelas orientações de enfermagem nos parece demonstrar a falta de estabelecimento de vínculo entre profissionais e pacientes durante a fase de hospitalização.

Em virtude do acelerado processo técnico e científico no contexto da saúde, a dignidade da pessoa humana, com frequência, parece ser relegada a um segundo plano. E a doença passou a ser o objeto do saber reconhecido cientificamente, desarticulada do ser que a abriga e no qual ela se desenvolve. 
Também os profissionais da área da saúde parecem gradativamente desumanizar-se, favorecendo a desumanização de sua prática ${ }^{(32)}$.

É importante ressaltar que a sobrecarga imposta pelo cotidiano do trabalho leva os profissionais de saúde a assistir de forma mecanizada, tecnicista e não-reflexiva, desvalorizando a humanização do cuidado. Da mesma maneira, as relações de trabalho vêm-se dando de modo pouco humanizado, interferindo diretamente na assistência ${ }^{(7)}$.

O mundo moderno exige profissionais de saúde cada vez mais capacitados, principalmente do ponto de vista tecnológico, exigindo atributos e conhecimentos para responder às demandas impostas pelos avanços técnicocientíficos. Dessa forma, as interações interpessoais acabam por assumir uma condição inferior, predominando a razão sobre a emoção e valorizando o ter em detrimento do $\operatorname{ser}^{(8)}$.

Logo, é imperiosa a promoção de um cuidar humanizado que preserve a dignidade do ser paciente, percebendo-o de forma holística e integral, caracterizando um encontro terapêutico, a partir do qual o cuidador necessita levar em consideração as fragilidades que atingem o paciente ${ }^{(8)}$.

Quando os clientes foram questionados sobre como colocariam as orientações na prática do seu dia-a-dia, afirmaram que seguiriam as orientações dos profissionais de saúde, fundamentadas em cuidados físicos e limpeza da ferida cirúrgica.

Nesse sentido, consideramos pertinente o reconhecimento de que a alta hospitalar é a transferência do cuidado do hospital para outros contextos de 
saúde. No hospital, o médico é o responsável legal pela alta hospitalar do paciente, mas o enfermeiro é considerado o coordenador do seu planejamento por atuar de forma integral, enquanto os demais membros da equipe de saúde oferecem intervenções episódicas ${ }^{(33)}$.

Além disso, cabe ao profissional da saúde decodificar, decifrar e perceber o significado da mensagem que o paciente envia, para só então estabelecer um plano de cuidado adequado e coerente com as suas necessidades. Para tanto, é preciso estar atento aos sinais de comunicação verbal e não-verbal emitidos pelos pacientes e seus familiares durante o processo de interação ${ }^{(20)}$.

Sobre a contribuição da orientação pós-operatória realizada pelo enfermeiro, 11 sujeitos afirmaram que contribui e reforça as orientações recebidas por outros profissionais de saúde.

Estudos mostram que o fornecimento de informações é a intervenção básica no planejamento da alta hospitalar, que os pacientes e seus cuidadores são capazes de identificar suas necessidades de informação e que estas dependem das suas condições de saúde e dos tipos de cuidados necessários após a alta. Porém, faz-se muito importante a forma como as informações são fornecidas, e os recursos usados podem ajudar na apreensão dos seus conteúdos e favorecer a satisfação com o processo ${ }^{(34,35)}$.

A satisfação dos clientes é diretamente proporcional ao processo de atendimento de suas expectativas e necessidades de cuidados de enfermagem. Assim, fica evidente que a metodologia utilizada pode mensurar 
os resultados de satisfação e contribuir para melhoria contínua, obtida por meio da mudança da cultura, dos valores e princípios dentro da organização, resultando numa clientela efetivamente protagonista do processo de busca da qualidade nos serviços de saúde ${ }^{(36)}$.

Os pacientes e familiares são elementos chave para a avaliação do planejamento da alta, por meio da satisfação ou insatisfação com o processo. A satisfação refere-se a uma avaliação baseada em reações cognitivas e afetivas em relação à estrutura, processo e resultados dos serviços de cuidado à saúde. Essa reação resulta da comparação do cuidado recebido com um critério subjetivo, ou seja, a percepção ou expectativa dos clientes ${ }^{(37)}$.

Dessa forma, conhecer a percepção do paciente sobre o cuidado de enfermagem recebido e os fatores que implicam na sua satisfação torna-se importante não apenas pelo fato de que o paciente satisfeito colabora com a assistência prestada e com o seu tratamento, mas também porque a opinião do paciente sobre o cuidado recebido fornece à equipe de enfermagem subsídios para planejar a assistência e prestar um serviço com qualidade ${ }^{(38)}$.

Vários estudos evidenciam a importância em dar explicações sobre a cirurgia, orientar sobre os procedimentos e atender ao paciente e familiares quanto às suas necessidades físicas, emocionais e espirituais, especialmente quando ameaçadas por ocorrência do procedimento cirúrgico ${ }^{(6,11,22,25,39)}$.

Sabe-se que o paciente se sente frágil no período perioperatório, uma vez que o ato anestésico cirúrgico gera ansiedade. Assim, um local humanizado pode ajudar a diminuir ou evitar esse sentimento, colaborando para que o indivíduo sinta-se mais seguro e confiante ${ }^{(40,41)}$. 
Quando solicitados a apresentar sugestões para o cuidado com os próximos pacientes, os participantes do estudo manifestaram-se, claramente, sobre a falta de cuidado humano $(56,25 \%)$ e falta de infraestrutura em recursos humanos $(31,25 \%)$, o que evidencia os problemas no estabelecimento da relação de confiança e vínculo entre a equipe de saúde e o paciente.

O cliente cirúrgico exige cuidados fundamentados nas necessidades evidentes e/ou potencializadas pela iminência do procedimento anestésico cirúrgico ou pelas ocorrências oriundas da dinâmica do preparo do ambiente, do indivíduo, respeitando seus valores e promovendo interações para melhorar sua condição de enfrentamento da cirurgia ${ }^{(22)}$.

Com as mudanças na prestação de serviços e no padrão de comportamento da sociedade, o cidadão comum passa a exigir qualidade ao consumir serviços e produtos, deixando de agir de forma passiva e condescendente. Ao profissional de enfermagem é solicitada uma atitude autoavaliativa, de reflexão acerca de seu comportamento diante dos desafios que a prática diária os impõe, o que tende a promover uma mudança de seus paradigmas e, possivelmente, evolução da profissão ${ }^{(15)}$.

Não podemos, portanto, ignorar os sentidos que o cliente atribui à experiência de participar dos cuidados de enfermagem na instituição hospitalar, cuidados estes experimentados como ação técnica, mas também como ação sensível, já que implicam um encontro entre pessoas, aquela que cuida e aquela que participa do cuidado, em que pese a dotação da espécie humana com órgãos de sentido e emoção ${ }^{(3)}$. 


\subsection{Análise Categorial Temática}

As categorias temáticas que emergiram a partir das entrevistas com os clientes e/ou familiares no domicílio foram:

1. Orientações focadas em técnicas básicas de enfermagem;

2. Sensação de ser bem cuidado;

3. Sensação de insegurança com o cuidado prestado;

4. Comunicação ineficaz.

\section{Categoria 1 - Orientações focadas em técnicas básicas de enfermagem}

Esta categoria emergiu a partir dos seguintes discursos:

"Ela me orientou, falou sobre as coisas que eu tinha que fazer, né?! Eu acho que foi tudo bem, eu não tenho queixa de lá".(E7)

"Fui muito bem atendido pelas enfermeiras, pelos enfermeiros, em termos de curativos, né?! Todas as minhas dúvidas em relação aos pontos, sobre a sonda... acho que é vesical, acho que chamava assim, né?! Os enfermeiros me passavam que não tinha nada, que tava tudo certinho, que não tinha problema, que era assim mesmo que era".(E11)

"Nos dois primeiros dias, eu não sei se como eu fiquei só deitada, então eram aqueles cuidados só com medicação, de colocar remédios no soro, então não tinha muito o que conversar para eles me ajudarem, né?! Porque eu não podia levantar. Aí, depois que eu tirei a sonda que eu precisei mais dos cuidados, para levantar... é, pra tomar banho".(E3) 
"Foi tudo explicado: como fazer em casa, como que tinha que fazer com a bolsa, quando começa a encher que ia esvaziar a bolsa. Foi tudo bem explicado, não saí com dúvida nenhuma lá de dentro".(E10)

Vimos que a enfermagem faz as orientações sobre os cuidados pósoperatórios baseada nas ações que julgam importantes, tais como: realização do curativo, administração das medicações no horário correto e higiene corporal. Mas, neste estudo, percebemos que desconsideram a complexidade das necessidades do cliente, não oferecendo a atenção que ele espera, como apoio, segurança e tranquilidade sobre os cuidados recebidos.

Dificilmente teremos todo o tempo que desejamos para atender um paciente, por isso os pequenos momentos devem ser bem aproveitados para que possamos melhorar a nossa assistência e individualizar o cuidado. O que percebemos é que, geralmente, um enfermeiro opta pelo cuidado físico, desconhecendo que o nível de satisfação do paciente está relacionado também com a comunicação feita durante a assistência de enfermagem prestada(18).

A equipe de enfermagem, por vezes, assume posição dogmática de detentora do saber, não se organizando para integrar o familiar acompanhante em uma metodologia de assistência planejada e compartilhada. Ao invés disso, o que se observa é a ocorrência de uma simples divisão de tarefas ou, em outros casos, a transferência de responsabilidades, ou seja, transmite ao outro o que deve fazer e como deve ser feito, ditando as normas que devem ser entendidas como certas e rigorosamente seguidas ${ }^{(42)}$. 
É oportuno destacar que a humanização do cuidado em saúde perpassa pelo respeito à individualidade da pessoa, ao mesmo tempo em que suscita uma percepção holística deste ser, extrapolando a compreensão biologicista da doença e contemplando os aspectos psicológicos, sociais e espirituais que influenciam no processo saúde-doença ${ }^{(8)}$.

Para o enfermeiro, a qualidade do cuidado está fundamentada em aspectos de comportamento ético, baseados em competência técnica. Em contrapartida, para o paciente, os atributos mais importantes para um cuidado de qualidade estão voltados para os aspectos interpessoais, como: demonstração de carinho, oferecimento de informações e orientações quanto aos procedimentos realizados, atendimento rápido às solicitações, ser bom ouvinte, ter competência e habilidade sobre o cuidado, ser humano perante o outro e, sobretudo, respeitar e atender às suas necessidades.

A identificação dos sentimentos e das necessidades dos pacientes no período pós-operatório propicia a reflexão sobre a forma de atuação da equipe de enfermagem e a implantação de estratégias que facilitem o relacionamento enfermeiro-paciente. A orientação sobre os procedimentos é fundamental para a diminuição do medo e da ansiedade. No intuito de melhorar a qualidade da assistência prestada, as estratégias de enfermagem precisam ser estabelecidas considerando a individualidade do paciente, bem como o que ele precisa, sente e espera ${ }^{(43)}$.

Nesse sentido, chama-se a atenção para o fato de que os pacientes estão deixando o hospital com insegurança para dar sequência ao seu tratamento. Relatos apontam que as orientações para a alta hospitalar constam simplesmente da entrega da receita médica, das informações verbais 
fornecidas oralmente pelo médico sobre os medicamentos, encaminhamentos para os cuidados específicos e, por fim, retorno ambulatorial. A orientação para a alta hospitalar vem sendo realizada quase sempre pelo médico, sem tempo hábil que lhe permita considerar as particularidades de cada um, como suas dificuldades de compreensão, seu estilo de vida, experiências vividas, crenças, mitos, ansiedade e medo. Observa-se que a orientação é fornecida no momento da saída do paciente do hospital, não sendo desenvolvida durante o período de internação. Nessa ocasião são feitas muitas orientações ao mesmo tempo, com o agravante de não serem realizadas por escrito, dificultando a compreensão do paciente e propiciando a ocorrência de $\operatorname{erros}^{(33,41)}$.

Percebemos, neste estudo, que a comunicação não-verbal não foi utilizada de forma efetiva, ou seja, com a função de complementar, contradizer e substituir a comunicação verbal, além de demonstrar sentimentos. Os profissionais de saúde precisam estar atentos para os gestos, posturas, expressões faciais, orientações do corpo, entre outros, o que pode demonstrar necessidades não expressadas verbalmente por seus pacientes.

Nesse sentido, os resultados deste estudo demonstram que o enfermeiro pode e tem oportunidade de individualizar o cuidado durante suas atividades diárias, nos momentos de realização de técnicas ou por meio de orientações e esclarecimentos de dúvidas do cliente e dos familiares, sempre preservando suas particularidades. 


\section{Categoria 2 - Sensação de ser bem cuidado}

Esta categoria emergiu a partir dos seguintes discursos:

"Eu me senti muito bem tratada, muito bem cuidada. O pessoal me atendeu muito bem durante a internação, durante o dia todo, a tarde toda... fui muito bem tratada". (E2)

"O profissionalismo deles, ou seja, o pessoal tinha todo aquele cuidado especial, de vestir a roupa, trocar a luva, fazer o curativo. E o tempo inteiro foi assim, os 6 dias que eu fiquei foi desse jeito. Então, o profissionalismo estava acima de tudo".(E5)

"Eu fui pro quarto tranquila. O pessoal muito competente, muito atencioso no que precisava fazer. Então eu acho que eu fui, além de bem tratada, emocionalmente muito tranquila, porque eu sabia que tava sendo cuidada por profissionais de competência".(E14)

"Eu fui muito bem atendida, não tenho o que reclamar de nada. Eu só tenho que agradecer".(E8)

"Eu acho que teve qualidade, eu achei o atendimento "VIP", achei que o pessoal atende muito bem. Eu não tenho o que reclamar".(E13)

Nessa categoria, podemos observar que os pacientes e seus familiares demonstraram estar satisfeitos com o cuidado recebido e com as orientações fornecidas pela equipe de enfermagem, devido ao atendimento das suas expectativas e favorecimento da continuidade do cuidado após a alta hospitalar. 
As instituições de saúde são aquelas, na estrutura social vigente, que devem preservar a vida das pessoas. Sabemos, também, que o ser humano tem códigos aprendidos ao longo de sua vida que Ihe conferem um "saber" do que é ser humano. Ele continua utilizando esses códigos quando está nas instituições de saúde e é com esses códigos que ele avalia o trabalho e o atendimento recebido ${ }^{(44)}$.

Perceber o outro requer uma atitude profundamente humana. Reconhecer e promover a humanização, à luz de considerações éticas, demanda um esforço para rever, principalmente, atitudes e comportamentos dos profissionais envolvidos direta ou indiretamente no cuidado do paciente ${ }^{(45)}$.

A comunicação interpessoal é a troca que fazemos entre as pessoas. Ela envolve as palavras que pronunciamos, que é só um terço dos nossos pensamentos, e todas as formas de comunicação que não as envolvem, ou seja, a comunicação não-verbal, que engloba dois terços dos nossos pensamentos e intenções e se expressa por meio do nosso modo de olhar, expressões faciais, gestos e posturas corporais, entre outros ${ }^{(44)}$.

Nesse sentido, este estudo demonstrou que, quando se sentiram percebidos e atendidos em suas necessidades, os pacientes sentiram-se bem cuidados e agradecidos aos profissionais de saúde.

A qualidade da comunicação estabelecida no cuidado com o cliente reflete-se nas suas atitudes, padrões de reações e participação no seu tratamento, implicando-se na eficácia de tais cuidados e na recuperação da sua saúde ou readaptação a uma nova condição de vida ${ }^{(3)}$. 
A interação estabelecida com o cliente no ato de cuidar emergiu das falas, objetivamente, pela citação dos momentos de conversa que os profissionais tiveram com os clientes. Comprova-se, assim, que a comunicação é um alicerce importante para que a relação de cuidado se estabeleça de forma efetiva e eficaz.

O sentimento de ser bem cuidado é decorrente do processo de atendimento que o profissional faz quando é competente em comunicação, permitindo a construção de identidades subjetivas e tendo como resultado uma clientela protagonista no processo de qualidade nos serviços de saúde.

$\mathrm{Na}$ visão dos pacientes e seus familiares, os fatores que favorecem a satisfação do cuidado prestado estão voltados para o levantamento das suas necessidades, avaliação das suas condições físicas, emocionais e sociais, além da participação ativa da equipe durante a internação hospitalar e de uma comunicação competente durante as orientações de enfermagem.

Assim, a satisfação com o planejamento da alta hospitalar está relacionada com o suprimento de informações que foram ao encontro das necessidades dos pacientes e familiares e possibilitaram o desenvolvimento de habilidades, dando-Ihes segurança para a continuidade do cuidado após a alta. A insatisfação com o planejamento da alta hospitalar tem conotação contrária, quando o processo não supre as expectativas dos envolvidos ${ }^{(46)}$. 


\section{Categoria 3 - Sensação de insegurança com o cuidado prestado}

\section{Esta categoria emergiu a partir dos seguintes discursos:}

"Fui bem atendido, eu achei bom... mas durante a internação eu acho que faltou atendimento por falta de funcionário, falta de enfermagem. A correria é muito grande, não dá pra atender todo mundo. Ao mesmo tempo que tá comigo, o outro tá chamando. Chegou a atrasar até o banho, mas é por falta de funcionário... não tem como ver uma qualidade nota 10".(E16)

"É... havia atendentes, técnicas, né... que me trataram com humanidade e respeito. Porém, outros chegavam a me humilhar, me largavam sozinha. Eu apertava a campainha, colocavam a comadre e falavam: 'olha, daqui a pouco eu volto pra tirar', e demoravam mais de uma hora, uma hora e meia. Eu cheguei até a marcar a hora. Eu sempre apertando a campainha para que elas retornassem. Imagine o incômodo de ficar com a comadre... Eu não vi a técnica. A falta de cuidado foi maior do que a atenção devida pra pessoa humana. Na minha opinião, alguns atendentes precisavam ter o curso de humanização e de conscientização, porque eu verifiquei que a gente não é robô, não é máquina. Quem não tem aptidão pra isso que vá procurar um curso de computador ou alguma coisa assim". (E6)

"A assistência da enfermagem... eu não me lembro de ter tido, de elas terem me orientado que era pra fazer isso e aquilo, eu não tive orientação nenhuma. Tinha lá aqueles meninos, que... olha, valeu!!! Mas das enfermeiras, não. Não foi nenhuma vez, ninguém me orientou disto aqui, do curativo. Nada, ninguém".(E9)

“... O que eu senti um pouquinho foi no terceiro turno, né?! No turno da noite. Que eles atendem, isso é claro... vieram, são atenciosos, coisa e tal. Mas eu não sei se faltam pessoas, se reduz o quadro ou se é a própria pessoa... eu achei um pouquinho mais duro. Deveria ser melhor, mais amável, mais 
chegado. Principalmente quando você vai dar um comprimido para gente, você fala 'oi' com um sorriso. É diferente quando você chega seco e fala: 'tó, tá na hora, engole', entendeu?!"(E15)

"A qualidade do cuidado acho que não apareceu. Acho que tinha que ter mais um pouquinho de atenção, porque quem está de acompanhante não sabe o que fazer... nem eu também".(E1)

"Olha, os funcionários são maravilhosos... não tive queixa de ninguém, só que eu acho que há necessidade, principalmente, de mais enfermeiros, viu?!" (E12)

A internação hospitalar é percebida como sendo uma experiência desagradável por quem a vivencia, uma vez que é permeada pelo medo do desconhecido, pela utilização de recursos tecnológicos, muitas vezes invasivos e dolorosos, pelo uso de uma linguagem técnica e rebuscada que aumenta a ansiedade do ser doente no que tange a seu quadro patológico, pela inquietação em estar em um ambiente estranho, de estruturas rígidas que o descaracteriza, partilhando o mesmo espaço físico com pessoas fora de seu convívio familiar e, ainda, pela preocupação com sua evolução clínica ${ }^{(8)}$.

A hospitalização, de maneira geral, desencadeia no indivíduo sentimentos negativos, pois, ao deparar-se com o problema de saúde, sente-se impedido de desempenhar muitas das suas atividades. A impessoalidade no ambiente hospitalar, a distância do convívio familiar, dos amigos, de seu meio social, e o fato de, mesmo que temporariamente, ter que submeter-se a um 
ambiente com normas e rotinas às quais não está habituado, pode gerar ansiedade, insegurança e insatisfação ${ }^{(22)}$.

Muitos são os medos que os clientes podem manifestar, entre eles: o medo do desconhecido, que se materializa ainda mais pela distância que se instala entre o paciente e seus familiares; medo de ficar sozinho; de perder sua autonomia pessoal e social, e por saber que o controle de sua vida está agora nas mãos de uma equipe ${ }^{(6)}$.

A maneira de falar e o que falamos têm especial importância no momento da avaliação, pois o uso de termos técnicos pode aumentar a insegurança do paciente que desconhece tal linguagem. A linguagem pode variar de acordo com o nível sociocultural, a região do país, a idade, entre outros fatores. Portanto, é importante estarmos abertos para ouvir diferentes termos e saber interpretá-los adequadamente, validando-os, se necessário, para que seja feita uma avaliação correta da história e necessidades do paciente. Estar consciente e atento ao fato de que não nos comunicamos apenas com palavras aumenta nossa percepção em relação ao cuidado com o aspecto não-verbal nas interações com os pacientes, tornando-nos assim mais vigilantes quanto às diversas reações apresentadas por eles ${ }^{(20)}$.

Para cuidar de outro ser humano é necessário mais que conhecimento e habilidade técnica. Durante a assistência ao paciente, o compromisso, a responsabilidade, o envolvimento e a atenção constituem elementos fundamentais. É necessário estar atento para reconhecer as necessidades do paciente, sejam elas de origem fisiológica ou psicossocial ${ }^{(43)}$. 
O cuidado em enfermagem, como uma prática assistencial humanizada, necessita estar centrado na necessidade de comunicação como estratégia de aproximar paciente-equipe, na reconstrução do relacionamento entre o profissional de enfermagem e o ser humano hospitalizado, repercutindo diretamente na qualidade do serviço prestado pelas instituições de saúde e no modo como esse serviço é percebido pelo usuário ${ }^{(8)}$.

Com o avanço tecnológico e científico e a modernização de procedimentos vinculados ao estabelecimento de controle, o enfermeiro passou a assumir cada vez mais encargos administrativos. Assim, na prática, a atenção individualizada acontece de forma mecânica, nos despertando para a necessidade de resgatar os valores humanísticos da assistência de enfermagem $^{(10)}$.

O enfermeiro tem que estar capacitado para enfrentar as dificuldades advindas desse processo, pois este Ihe traz uma clientela cheia de incertezas diante das mudanças do dia-a-dia. Para ampliar o cuidado diante dessa situação, a competência em comunicação faz-se cada vez mais necessária. Somente assim é possível continuar oferecendo cuidado interdisciplinar, personalizado, competente e humanitário aos clientes que confiam em nossa capacidade profissional ${ }^{(17,20,26)}$.

Atualmente, o indivíduo que necessitar de um atendimento na rede de serviços de saúde, tanto pública quanto privada, terá, além da própria fragilidade em que passa, uma desagradável sensação de insegurança, pois irá precisar da atenção de um conjunto de trabalhadores de saúde para assimilar o seu sofrimento, entender o risco e a qualidade do comprometimento que vem 
passando e intervir no sentido de lhe garantir uma solução e alterar, na medida em que a tecnologia permitir, a situação individual e coletiva que se relaciona com o processo de produção do seu problema ${ }^{(47)}$.

A qualidade da assistência de enfermagem é algo a ser almejado todos os dias, ao realizarmos todo e qualquer tipo de atividade voltada à recuperação do paciente, preocupando-se não somente com o 'fazer', e sim com o 'fazer bem feito'. Para tanto, se faz necessário um repensar de nossa prática diária, reavaliando como tem sido nosso comportamento diante das inúmeras responsabilidades que nos são confiadas, assim como nosso conjunto de valores e motivações para o trabalho ${ }^{(15)}$.

Como confirmamos nesta pesquisa, dificilmente teremos todo o tempo que desejamos para atender a um paciente, por isso, os pequenos momentos devem ser bem aproveitados para que possamos, assim, melhorar a nossa assistência e individualizar o cuidado ${ }^{(18)}$.

Desse modo, os profissionais de enfermagem precisam utilizar a comunicação como instrumento para humanizar o cuidado, dialogando com o paciente visando a esclarecer dúvidas quanto ao seu tratamento, exames, diagnósticos ou procedimentos clínicos, minimizando a ansiedade causada pela sua condição de passividade imposta pela doença e hospitalização ${ }^{(8)}$. 


\section{Categoria 4 - Comunicação ineficaz}

Esta categoria emergiu dos seguintes relatos dos entrevistados:

"Podia melhorar na informação, né? Porque às vezes, assim... antes eu perguntava para os enfermeiros alguma coisa, sabe?! Quando será que vai tirar o meu dreno? Aí ele falava alguma coisa que eu não entendia... aí é que eu fiquei ansiosa, entendeu?! Oito dias não é fácil".(E3)

"Eles avisam a família que a gente vai para o quarto, aí a família vai correndo. Chega lá, minha filha, espera 2, 3 horas. Que ainda não tem quarto, que não sei que lá, e fica aquele rolo. Eles nervosos lá fora e a gente nervosa lá dentro". (E4)

"Eu fiquei com medo, com insegurança, tal, tal... e por ser a primeira vez... É... mas tudo bem, tive que encarar. Era o único jeito... não tinha remédio, né?! A coisa era fazer a cirurgia".(E11)

"Quando você questiona alguma coisa são os técnicos que fazem o atendimento. Eu acho que deixa a desejar, deixa mesmo... não sei qual que é a orientação que o profissional tem que ter para que tenha interação com os pacientes. Talvez seja por um acúmulo de trabalho que ele deixa de fazer isso. Agora, essa parte administrativa eu já não sei”. (E9)

Os sujeitos do estudo referiram-se a ansiedade e medo pela falta de informação e, embora mantivessem aparência calma durante a entrevista, observamos que a falta de informação gerou esses sentimentos e que as dúvidas aumentavam o nível de ansiedade durante o período de recuperação pós-operatória. 
Estudos confirmam nossos resultados, afirmando que na área da saúde é fundamental saber interagir com pessoas, pois, a todo momento, pelos corredores dos hospitais, nos ambulatórios, salas de emergência, leitos de pacientes e salas de cirurgias, surgem conflitos originados de uma atitude não compreendida ou mesmo de uma reação inesperada. É de se esperar que isso aconteça porque os profissionais da área da saúde têm como base do seu trabalho as relações humanas, sejam elas com o paciente e seus familiares ou com a equipe multidisciplinar. Assim, não se pode pensar na ação profissional sem levar em consideração a importância do processo comunicativo nela inserido. Nesse sentido, a escrita, a fala, as expressões faciais, a audição e o tato são formas de comunicação amplamente utilizadas, conscientemente ou não ${ }^{(20)}$.

Os pacientes e seus familiares à espera de uma cirurgia podem apresentar medo e ansiedade relacionados ao período pós-operatório e ao risco de complicações durante e após a cirurgia. Sabe-se que o paciente com dúvidas em relação à cirurgia e ao tipo de anestesia a que será submetido poderá apresentar ansiedade acentuada, interferindo de forma negativa na recuperação pós-operatória( ${ }^{(43)}$.

A ansiedade é uma resposta antecipada a uma experiência que ameaça o paciente, sua integridade corporal ou mesmo a própria vida. É definida como uma reação normal ao estresse e à ameaça de um dano. Sentimentos de desesperança e inadequação podem estar presentes, acompanhados de uma sensação de alienação e insegurança ${ }^{(48)}$. 
Reconhecer os sentimentos do outro é fundamental para o enfermeiro, pois é por meio dessa compreensão que ele percebe as necessidades do paciente e pode realizar um plano de cuidado sistematizado, considerando a pessoa como um todo e desenvolvendo postura empática. Assim, a comunicação competente pode ser considerada como um poderoso instrumento para se prestar assistência adequada ${ }^{(16,17)}$.

Sabe-se que a comunicação adequada é aquela que tenta diminuir conflitos, mal-entendidos e atingir objetivos definidos para a solução de problemas detectados na interação com os pacientes, e é nesse campo interacional que as pessoas se percebem, partilham o significado de ideias, pensamentos e propósitos, alterando ou mantendo seus significados num processo de interação com os outros e o ambiente, o que lhes permite traçar metas e visualizar meios para atingi-las ${ }^{(20,26)}$.

Em relação ao contexto da saúde, no processo de cuidado aos pacientes devem ser consideradas algumas dificuldades, como: a adaptação ao novo ambiente, ter que permanecer isolado dos seus familiares e compreender muitas terminologias e exigências para as quais nem sempre se está preparado ${ }^{(38)}$.

Este estudo nos possibilitou compreender que o uso ineficaz da comunicação e a carência de cuidado por parte de alguns profissionais implicam uma série de problemas que repercutem nas condições de recuperação dos indivíduos. 
A comunicação na relação paciente-profissional de enfermagem mostrase como um instrumento básico na construção de estratégias que almejem um cuidado humanizado, como, por exemplo, utilização de uma linguagem acessível, valorização da escuta ativa, de um sorriso que expresse confiança, de um olhar que demonstre tranquilidade, de um toque carinhoso que proporcione apoio e conforto, e uma palavra de ânimo que eleve a autoestima do paciente ${ }^{(8)}$.

A importância de oferecer uma assistência de enfermagem planejada e continuada aos pacientes e seus familiares durante a internação cirúrgica é o que faz a diferença, pois um atendimento prestado em tais moldes pode contribuir para aliviar a tensão dos envolvidos, na medida em que contempla o fornecimento de informações que Ihes permitem enfrentar a situação com menos ansiedade e incertezas. Com isso, o paciente e o acompanhante podem sentir maior confiança na equipe ${ }^{(49)}$.

Os clientes têm necessidade de receber informações, atenção e apoio num processo de relacionamento terapêutico, como um cuidado especial. Para isso, é fundamental estarmos atentos em decodificar, decifrar e perceber o significado da mensagem que o paciente envia, para só então estabelecer um plano de cuidado adequado e coerente com as suas necessidades ${ }^{(20)}$.

A assistência à saúde passa por grandes transformações. Na área hospitalar, é cada vez mais comum a importância da obtenção de lucros para as instituições, e os enfermeiros são responsáveis por gerenciar grande parte dessa tarefa. Assim, eles se tornam burocráticos, hipertrofiando as atividades 
gerenciais, e se esquecem da importância da humanização da assistência ao paciente ${ }^{(40)}$.

Observa-se, pelos relatos dos participantes, que o enfermeiro não está centrado no planejamento de forma humanizada e sistemática, encontrando-se ausente nesse processo, muitas vezes sendo confundido com os outros membros da equipe de enfermagem.

O enfermeiro é o profissional que coordena e gerencia todo o processo de assistência a ser desenvolvido em relação ao paciente, e tudo o que o envolve no contexto da instituição hospitalar. $O$ paciente e suas especificidades, suas necessidades, sua alta ou recuperação, constituem a principal razão da assistência de enfermagem, a qual necessita, portanto, ser realizada eficientemente, com comprometimento de quem a desenvolve, garantindo qualidade do cuidado prestado e, principalmente, a satisfação do paciente e seus familiares ${ }^{(15)}$.

Estudos mostram que os profissionais de saúde têm conhecimento da necessidade e importância de orientar pacientes e familiares para a continuidade da recuperação, porém, não conseguem alcançar esta meta devido à escassez de pessoal, sobrecarga de trabalho, longas jornadas, etc $^{(40,45)}$.

Este estudo confirma que ser competente em comunicação é uma habilidade fundamental a ser adquirida por enfermeiros, sejam eles docentes ou atuantes em outra atividade da prática do cuidar, e que a atenção a essa 
habilidade Ihes possibilitará um cuidar consciente, verdadeiro e transformador $^{(17)}$.

Considerando que a Enfermagem se apresenta como um encontro entre o ser que cuida e o ser cuidado, é possível destacar que essa profissão exerce um papel fundamental na prática do cuidar humanizado, a partir de uma interação efetiva com o indivíduo hospitalizado, oportunizando uma comunicação genuína, como um processo que visa à criação de espaços que viabilizem a satisfação do ser doente em suas necessidades, ao permitir a este partilhar suas vivências, angústias, medos, ansiedades e inseguranças. Nesse enfoque, torna-se importante que o cuidado, no sentido de uma prática assistencial humanizada, esteja centrado na necessidade de comunicação como estratégia de aproximar o cuidador do ser cuidado ${ }^{(8)}$.

Dessa forma, o profissional de enfermagem possui um papel fundamental no cuidado humanizado, devendo sentir-se corresponsável e envolvido com o cuidado à pessoa ${ }^{(6)}$. 
6. Considerações Finais 
Neste estudo, em que nos propusemos a conhecer as orientações pósoperatórias fornecidas pela equipe de enfermagem a pacientes e/ou familiares de uma instituição privada e apreender a percepção destes indivíduos acerca das orientações recebidas, foi possível observar que a equipe de enfermagem mantém seu foco principal de cuidado em técnicas instrumentais da profissão, em detrimento ao cuidado holístico aos indivíduos, que visam a necessidades físicas, emocionais, sociais e espirituais.

Consideramos oportuno reforçar a condição da presença do enfermeiro como coordenador do cuidado em saúde, planejando o cuidado, capacitando sua equipe, tornando real a educação permanente, realizando experiências interdisciplinares e, desse modo, oferecendo recuperação competente e segura aos seus clientes.

Este estudo também possibilita a compreensão de que uma situação de hospitalização e, especialmente, um procedimento cirúrgico podem gerar medo e insegurança e até sentimentos contraditórios de sentir-se, em alguns momentos, muito bem cuidado e, em outros, sentir insegurança quanto ao cuidado recebido. Observou-se que, quando os pacientes e seus familiares são bem orientados, demonstram estar satisfeitos com o cuidado recebido e com as orientações fornecidas pela equipe de enfermagem, devido ao atendimento das suas expectativas e favorecimento da continuidade do cuidado após a alta hospitalar. Esta pesquisa, bem como nossa experiência profissional, nos permitiu perceber que os clientes de instituições privadas são mais capazes de formular críticas ao atendimento que recebem, o que muito se ampliou nas entrevistas com os clientes em seus domicílios, embora, alguns destes, quando 
questionados sobre o cuidado recebido pelos profissionais da equipe de enfermagem, relataram sentir-se constrangidos em responder questões sobre a avaliação do cuidado, alegando preocupações com a associação entre o convênio e sua ocupação profissional.

Considerar a necessidade de uma comunicação adequada é viabilizar a possibilidade de diminuir conflitos, ansiedade e os temores gerados pelo estresse do procedimento cirúrgico e, além disso, estar presente e atento a todos os sinais emitidos. Isso exige envolvimento, sensibilidade, atenção, compreensão, diálogo, apoio, conforto e esclarecimento de dúvidas.

As conclusões deste estudo nos levam a perceber que, para um cuidado de enfermagem efetivo, é preciso que a equipe esteja conscientizada e preparada para fazer a diferença no cuidado, compreendendo o paciente em toda a sua complexidade, avaliando amplamente os aspectos físicos, emocionais, sociais e espirituais envolvidos nas interações, atuando em equipe de forma comunicativa e competente, ouvindo o outro e agindo de forma coerente com a prática de sua profissão, consciente de seu papel como profissional de saúde e cidadão. Cabe a nós, profissionais de enfermagem, buscar sempre a atualização na área, avaliar nossa assistência e questionar nossa responsabilidade diante dos resultados e reflexões aqui apresentados, para que possamos, continuamente, melhorar o nível de satisfação dos clientes em relação aos serviços prestados e, assim, compreender que cuidar com qualidade é estar com o outro ser humano em situação de igualdade, dignidade e respeito. 
7. Referências 
1. Cruz EA, Varela ZMV. Admissão em centro cirúrgico como espaço de cuidado. Rev Eletrôn Enferm. 2007; 14: 51-8.

2. Talento B, Jean Watson. In: George JB. Teorias de enfermagem: os fundamentos à prática profissional. $4^{\mathrm{a}}$ ed. Porto Alegre: Artes Médicas Sul; 2000. p. 253-65.

3. Ferreira MA. A comunicação no cuidado: uma questão fundamental na enfermagem. Rev Bras Enferm. 2006; 59: 237-330.

4. Barcelos LMS, Alvim NAT. Conversa: um cuidado fundamental de enfermagem na perspectiva do cliente hospitalizado. Rev Bras Enferm. 2003; 56: 236-41.

5. Waldow VR. Cuidado humano: o resgate necessário. $3^{\mathrm{a}}$ ed. Porto Alegre: Sagra Luzzatto; 2001.

6. Carvalho R, Bianchi ERF. Enfermagem em centro cirúrgico e recuperação. Barueri (SP): Manole; 2007.

7. Collet N, Rozendo CA. Humanização e trabalho na enfermagem. Rev Bras Enferm. 2003; 56: 189-92.

8. Morais GSN, Costa SFG, Fontes WD, Carneiro AD. Comunicação como instrumento básico no cuidar humanizado em enfermagem ao paciente hospitalizado. Acta Paul Enferm. 2009; 22: 323-27. 
9. Mathiasi NPA. Qualidade, custo e humanização: um desafio para os hospitais. Rev Ícaro. 2005; 20.

10. Bedin E, Ribeiro LBM, Barreto RASS. Humanização da assistência de enfermagem em centro cirúrgico. Rev Eletron Enferm. 2004; 6: 400-9.

11. Cianciarullo TI, Gualda DMR, Melleiro MM, Anabuki MH. Sistema de assistência de enfermagem: evolução e tendências. $3^{a}$ ed. São Paulo: Ícone; 2001.

12. Ministério da Saúde. HumanizaSUS: Política Nacional de Humanização. Programa Nacional de Humanização da Assistência Hospitalar/PNHAH. Brasília; 2004.

13. Conselho Federal de Enfermagem - COFEN. Código de ética dos profissionais de enfermagem. Resolução n²40/2000. Capítulo I. Brasília (DF): COFEN; 2000.

14. Carvalho R, Bianchi ERF. Enfermagem em centro cirúrgico e recuperação. In: Fortes PAC. Ética e saúde: questões éticas, deontológicas e legais, tomada de decisões, autonomia e direitos do paciente, estudo de casos. São Paulo: EPU; 1998; 369.

15. Barbosa LR, Antonieto MR. Relações entre qualidade da assistência de enfermagem: revisão integrativa da literatura. Rev Bras Enferm. 2008; 61: 366-70. 
16. Silva MJP. Percebendo o ser humano além da doença - o não verbal detectado pelo enfermeiro. Rev Nurs. 2001; 41: 14-20.

17. Braga EM. Comunicação competente - visão de enfermeiros especialistas em comunicação. Acta Paul Enferm. 2007; 20: 410-4.

18. Silva MJP. Qual o tempo do cuidado?: humanizando os cuidados de enfermagem. $2^{a}$ ed. São Paulo: Loyola; 2006.

19. Bordenave JED. O que é comunicação? São Paulo: Brasiliense; 2003.

20. Silva MJP. Comunicação tem remédio: a comunicação nas relações interpessoais em saúde. $4^{\mathrm{a}}$ ed. São Paulo: Loyola; 2006.

21. Azevedo RCS. A comunicação como instrumento do processo de cuidar visão do aluno de graduação. Rev Nurs. 2002; 5 (45): 19-23.

22. Carneiro MTR. Análise da autonomia de indivíduos internados em enfermarias cirúrgicas de um hospital universitário [Dissertação]. Botucatu: Faculdade de Medicina, Universidade Estadual Paulista; 2008.

23. Pellizzetti N. Análise da implantação da visita pós-operatória de enfermagem em um hospital universitário [Dissertação]. São Paulo: Escola de Enfermagem, Universidade de São Paulo; 1997.

24. Gaidzinsk RR, Kimura M. Entrevista e exame físico: instrumento para levantamento de dados. In: Campedelli MC, organizador. Processo de enfermagem na prática. $2^{\mathrm{a}}$ ed. São Paulo: Ática; 2000. p.66-88. 
25. Risso ACMCR. A comunicação da suspensão de cirurgias pediátricas: motivos e sentimentos envolvidos no processo [Dissertação]. Botucatu: Faculdade de Medicina, Universidade Estadual Paulista; 2008.

26. Stefanelli MC, Carvalho EC. A comunicação nos diferentes contextos da enfermagem. Barueri: São Paulo: Manole; 2005. Série Enfermagem.

27. Littlejohn SW. Fundamentos teóricos da comunicação humana. Tradução A. Cabral. Rio de Janeiro: Zahar; 1982.

28. Minayo MCS. O desafio do conhecimento: pesquisa qualitativa em saúde. 9a ed. São Paulo: Hucitec; 2006.

29. Minayo MCS. Pesquisa Social: teoria, método e criatividade. Petrópolis: Vozes; 2007.

30. Ministério da Saúde. Resolução n.196/96. Sobre pesquisa envolvendo seres humanos. Bioética. 1996; 4 (2): 14-25.

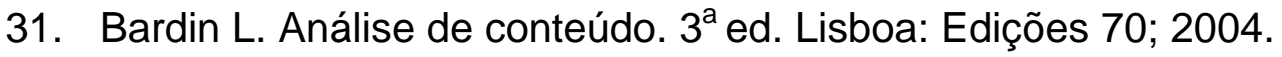

32. Backes DS, Lunardi VL, Lunardi Filho WD. A humanização hospitalar como expressão ética. Rev Latino-am Enferm. 2006; 14(1):132-5.

33. Huber DL, McClelland E. Patient preferences and discharge planning transitions. J Prof Nurs. 2003;19:204-10. 
34. Anthony MK, Hudson-Barr D. A patient-centered model of care for hospital discharge. Clin Nurs Res. 2004;13:117-36.

35. Ganzella M, Zago MMF. A seleção das informações para o planejamento da alta hospitalar do paciente. Enferm Bras. 2006; 5:268-75.

36. Lopes JL, Cardoso MLAP, Alves VLS, D’Innocenzo M. Satisfação de clientes sobre cuidados de enfermagem no contexto hospitalar. Acta Paul Enferm. 2009; 22 (2):136-41.

37. Bull MJ, Hansen HE, Gross CB. Predictors of elder and family caregiver satisfaction with discharge planning. J Cardiovasc Nurs. 2000;14:76-87.

38. Oliveira AML, Guirardello EB. Satisfação do paciente com os cuidados de enfermagem: comparação entre dois hospitais. Rev Esc Enferm USP. 2006; 40:71-7.

39. Kawamoto EE. Enfermagem em clínica cirúrgica. $2^{a}$ ed. São Paulo: EPU; 1999.

40. Aquino CP, Caregnato RCA. Percepção das enfermeiras sobre humanização da assistência perioperatória. Rev Sobecc. 2005; 10(2):1621.

41. Pompeo AD, Pinto MH, Cesarino CB, Araujo RRDF, Poletti NAA. Atuação do enfermeiro na alta hospitalar: reflexões a partir dos relatos de pacientes. Acta Paul Enferm. 2007; 20: 345-50. 
42. Grazziano ES, Bianchi ERF. Nível de ansiedade de clientes submetidos a cineangiocoronariografia e de seus acompanhantes. Rev Latino-am Enferm. 2004; 12: 168-74.

43. Silva EA, Vicente ML, Gutierrez PP, Galdeano LR. Sentimentos e necessidades do paciente na unidade de recuperação anestésica. Rev Sobecc. 2008; 13(3): 34-40.

44. Silva MJP. A importância da comunicação nos processos de qualidade. Rev Nurs. 1998; 1:20-6.

45. Backes DS, Lunardi VL, Lunardi Filho WD. A humanização hospitalar como expressão ética. Rev Latino-am Enferm. 2006; 14:132-5.

46. Ganzella M, Zago MMF. The hospital discharge as evaluated by patients and their caregivers: an integrative literature review. Acta Paul Enferm. 2008; 21: 351-5.

47. Merhy EE. Saúde: a cartografia do trabalho vivo. São Paulo: Hucitec; 2002.

48. Brunner LS, Suddath DS. Tratado de enfermagem médico-cirúrgica. $11^{\mathrm{a}}$ ed. Rio de Janeiro: Guanabara Koogan; 2009.

49. Colenci R, Abdala KM, Braga EM. A família na sala de espera do centro cirúrgico. Rev Sobecc. 2004; 9:13-20. 
Anexos 


\section{Anexo I}

\section{unesp Universidade Estadual Paulista Faculdade de Medicina de Botucatu}

Distrito Rubião Junior, $s / n^{0}-$ Botucatu - S.P.

CEP: $18.618-970$

Fone/Fax: (0xx14) 3811-6143

e-mail secretaria: capellup@fmb.unesp.br

e-mail coordenação: tsarden@fmb.unesp.br

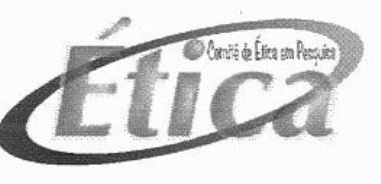

Registrado no Ministério da Saúde em 30 de abril de 1997

Botucatu, 09 de setembro de 2008

Of. 390/08-CEP

Ilustríssima Senhora

Prof ${ }^{a} D r^{a}$ Eliana Mara Braga

Departamento de Enfermagem da

Faculdade de Medicina de Botucatu.

Prezada Prof ${ }^{a}$ Eliana,

De ordem do Senhor Coordenador deste CEP, informo que o Projeto de Pesquisa "Avaliação da qualidade do cuidado no período pós operatório: utilizando a comunicação como instrumento", a ser conduzido por Ana Paula Ribeiro, orientada por Vossa Senhoria, recebeu do relator parecer favorável, aprovado em reunião de 07/07/2008.

A recomendação contida no ofício $272 / 08$ foi satisfatoriamente atendida, estando o projeto em condições de ser iniciado.

Situação do Projeto: APROVADO. Ao término deste projeto apresentar ao CEP Relatório Final de Atividades.

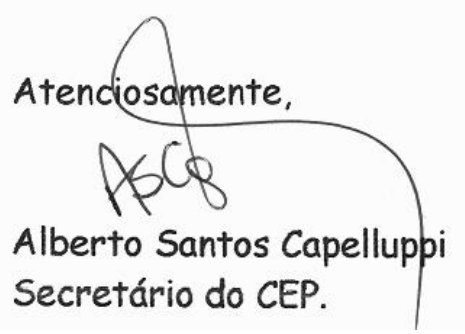




\section{Anexo II}

\section{TERMO DE CONSENTIMENTO LIVRE E ESCLARECIDO}

Pesquisa: "Percepção do cliente quanto ao cuidado de enfermagem no período pósoperatório".

O objetivo da presente pesquisa é conhecer as orientações pós-operatórias fornecidas pela equipe de enfermagem a pacientes e/ou familiares de uma instituição privada, e apreender a percepção desses indivíduos acerca das orientações recebidas.

Solicito seu consentimento para participar da entrevista, respondendo perguntas sobre o cuidado no período pós-operatório. Suas informações serão gravadas em aparelho audio digital e utilizadas exclusivamente pela pesquisadora que posteriormente irá transcrever e destruir o conteúdo gravado. A pesquisadora manterá sigilo sobre sua identidade e estará disponível para responder quaisquer perguntas, e você poderá retirar seu consentimento a qualquer momento.

Tendo sido satisfatoriamente informado sobre a pesquisa "Percepção do cliente quanto ao cuidado de enfermagem no período pós-operatório" sob responsabilidade de Ana Paula Ribeiro Razera, Enfermeira da Unidade de Tratamento Cirúrgico II do Hospital Unimed de Bauru, orientada pela Profa. Dra. Eliana Mara Braga, do Departamento de Enfermagem da Faculdade de Medicina de Botucatu - UNESP, declaro que concordo em participar da mesma, respondendo as perguntas apresentadas em entrevista.

\section{CONFIDENCIALIDADE}

Eu, , entendo que qualquer informação obtida sobre mim será confidencial. Eu também entendo que meus registros de pesquisa estarão disponíveis para revisão da pesquisadora. Ficou esclarecido que minha identidade não será revelada em nenhuma publicação desta pesquisa; por conseguinte, consinto na publicação para propósitos científicos.

\section{DIREITO DE DESISTÊNCIA}

Eu entendo que estou livre para recusar minha participação neste estudo ou para desistir a qualquer momento, e que minha decisão não afetará adversamente meu tratamento na clínica ou causar perda de benefícios para os quais eu poderei ser indicado.

\section{CONSENTIMENTO VOLUNTÁRIO}

Eu certifico que li ou foi-me lido o texto de consentimento e entendi seu conteúdo. Uma cópia deste formulário ser-me-á fornecida. Minha assinatura demonstra que concordei livremente em participar deste estudo.

\section{Assinatura do Participante da Pesquisa:}

Data:

Assinatura da Pesquisadora Responsável:

Data:

Dados da Pesquisadora: Ana Paula Ribeiro Razera

Rua: Caiapós, no 1-17, Vila Cardia, Bauru/SP

telefone (14) 9615-2193, email: anapaularibeiro82@hotmail.com

Dados da Orientadora: Prof ${ }^{\mathrm{a}}$ Dra.Eliana Mara Braga

Departamento de Enfermagem - FMB - Campus de Botucatu - UNESP,

Telefone (14) 3811-6070, email: elmara@fmb.unesp.br 


\section{Anexo III \\ FORMULÁRIO PÓS-OPERATÓRIO}

\section{Identificação do paciente}

Nome Mês/Ano

Idade Sexo Estado civil

Data da cirurgia _______ Cirurgia realizada

Especialidade Tipo de anestesia

Endereço

Telefone para contato Data da visita pós-operatória

\section{Nível de consciência}

( ) Inconsciente ( ) Consciente ( ) Comunicativo ( ) Outro. Especificar

\section{Tipo de cirurgia}

( ) Eletiva ( ) Urgência ( ) Emergência

\section{Intercorrências no ato anestésico / cirúrgico}

( ) Não ( ) Sim.

Especifique

\section{Opinião do paciente}

a) Você recebeu algum tipo de orientação de enfermagem no período pós-operatório?

( ) Não ( ) Sim.

Especifique

b) Quais dessas orientações você acha importante de serem seguidas? 
c) Como você irá colocar essas orientações de enfermagem na prática do seu dia-a-dia?

d) A visita pós-operatória de enfermagem contribuiu de alguma forma para the esclarecer dúvidas?

( ) Não ( ) Sim.

Especifique

e) Gostaria de fazer alguma sugestão para o cuidado com os próximos pacientes?

\section{Anotações}

Data da alta hospitalar

Evolução de enfermagem 


\section{Anexo IV}

\section{FORMULÁRIO PÓS-ALTA HOSPITALAR}

Anotação pós-alta hospitalar através da visita domiciliar

Data:

Nome do entrevistado:

Grau de parentesco:

1. Como você se sentiu durante a internação para a realização da cirurgia?

2. Na sua opinião, as orientações recebidas no pós-operatório significaram que existe um cuidado de enfermagem adequado? 